\title{
Labor Market Engagement and the Health of Working Adults: Evidence from India ${ }^{\ddagger}$
}

\author{
Archana Dang ${ }^{*}$, Pushkar Maitra** and Nidhiya Menon ${ }^{* * *}$
}

April 2018

\begin{abstract}
Driven by rapid income growth, labor market transitions in the nature of jobs, and lifestyle factors, there has been a widespread increase in rates of overweight and obesity in many developing countries. This paper examines the effect of occupational engagement and work intensity on the weight of urban working women and men in India. Using nationally representative data, specifications that reflect different definitions of work, and empirical methods that correct for the influence of unobservables, we document that labor market inactivity is positively associated with BMI. Women engaged in white collar work are about $4.12 \%$ heavier than those in blue collar work. For working men, the comparable estimate is about $4.81 \%$. Our paper adds to the fairly limited evidence on the relationship between the labor market engagement and health in developing countries.
\end{abstract}

Key Words: Excess Weight, Labor Market, Gender, India

JEL Codes: I12, I15, O12

\footnotetext{
${ }^{\ddagger}$ We thank Sonia Bhalotra, Diana Contreras, Gaurav Datt, Ashwini Deshpande, Parikshit Ghosh, David Johnston, Kevin Lang, Albert Ma, J. V. Meenakshi and conference and seminar participants at the Australian Health Economics Society Meetings, Delhi School of Economics, Indian Statistical Institute, and South Asian University for helpful comments and discussions. Menon thanks the Institute for Economic Development (IED) at Boston University for its hospitality in the Fall 2017 semester. The usual caveat applies."Archana Dang, Delhi School of Economics, University of Delhi, Delhi 110007, India. archana@econdse.org. ${ }^{* *}$ Pushkar Maitra, Department of Economics, Monash Business School, Monash University, Clayton Campus, VIC 3800, Australia. Pushkar.Maitra@monash.edu. ${ }^{* * * *}$ Nidhiya Menon, Department of Economics and International Business School, Brandeis University, Waltham, MA 02454, USA.nmenon@brandeis.edu.
} 


\section{Introduction}

One of the striking global health trends in the recent past has been the rapid increase in the rates of overweight and obesity in both developed and developing countries. According to Lancet (2016), over the period 1975-2014, the number of obese individuals in the world has increased from 105 million to 641 million. Obesity is increasingly viewed as a global pandemic, with more obese people than under-weight in the world today. Indications are that the problem is going to worsen in the future, thus contributing to the global burden of health.

Policy makers in developing countries therefore face an obesity led increase in projected public health expenditures. This is especially true in India where high rates of economic growth in the last two decades and the resultant increase in income and wealth have been associated with an increase in the proportion of the population that is overweight or obese. India currently has the third highest number of overweight and obese individuals among all countries, with $20 \%$ of adults and $11 \%$ of adolescents characterized as belonging to this category (Lancet (2014)). The health implications are substantial, with excess weight being positively associated with chronic health risks like hypertension and diabetes. Understandably, the impact of these diseases on household budgets is likely to be substantial. Engelgau, et al. (2012) argue that in India the risk of impoverishment due to non-communicable diseases like heart disease is about $40 \%$ higher as compared to that due to communicable diseases, and households in India with a heart disease patient are estimated to spend up to a third of their annual income on health expenses.

Weight gain is the result of high energy intake or low energy expenditure or a combination of both (Roberts and Leibel (1998)). In the Indian context, evidence suggests that there has been no significant increase in average energy intake over time; rather there has been a secular decline in average energy intake (Deaton and Drèze (2009) and Ramachandran (2014)). Therefore, an analysis of weight should account for energy expenditure in order to provide a comprehensive 
picture of underlying dynamics. This is the lens that we employ here. Specifically, using nationally representative data from India, we examine the effect of occupational activity on the weight of urban working Indians. Occupational activity is measured by sector of work and intensity of work. ${ }^{1}$ We focus on urban residents as our prior research (Maitra and Menon (2017)) shows that the phenomenon of overweight and obesity is especially pronounced in urban India.

Tailoring measures of physical intensity to reflect the structure of occupations specific to India, this paper provides new evidence on this topic from a country where the number of over-nourished people is increasing dramatically. We employ several empirical specifications to analyze the relationship between occupational activity levels and weight. Conditional on observed covariates, controls for location and time and conditioning for the effect of unobservables, we find that being employed in a low activity occupation results in higher weight. In particular, women employed in white collar work are approximately 1.01 kilograms $/$ meter $^{2}\left(\mathrm{~kg} / \mathrm{m}^{2}\right)$ heavier than women in blue collar work (a difference of 4.12\%). The corresponding relative difference for working men is $1.18 \mathrm{~kg} / \mathrm{m}^{2}$, a difference of $4.81 \%$. We find comparable results when work is measured in terms of its intensity in urban regions of India. Our results are robust to a variety of specification tests.

This paper adds to the fairly limited evidence on the relationship between labor market engagement and the health of working men and women in developing countries. It is consistent with the sparse evidence on the relationship between the physical strenuousness of occupations and weight in other developing countries. Colchero, et al. (2008) using longitudinal data from Philippines finds that BMI among women employed in occupations involving low and medium physical activity were respectively 0.29 and $0.12 \mathrm{~kg} / \mathrm{m}^{2}$ greater compared to women employed in heavy physical activity occupations. Adair (2004), also using data from Philippines, shows that

\footnotetext{
${ }^{1}$ The intensity of work refers to the physical demands or the energy expenditure associated with each occupation. Methods to capture the intensity of work are well established and we discuss these in detail in Section 2.
} 
improvements in socioeconomic status, a reduction in the number of hours worked, and urban residence, were all systematically positively correlated with weight gain. Similar results have been obtained from China. Paeratakul, et al. (1998) finds that women employed in physically strenuous occupation had $0.42 \mathrm{~kg} / \mathrm{m}^{2}$ lower BMI than women in relatively less physically strenuous jobs; Bell, et al. (2001) finds that both men and women engaged in low and moderate physical activity at work experienced large weight $(>5 \mathrm{~kg})$ gains as compared to women engaged in heavy physical activity. These studies emphasize that weight status is closely aligned with the physical intensity of work in developing countries, and underscore the importance of accounting for occupation-related energy expenditure in understanding determinants of weight. ${ }^{2}$

We build on this existing literature in two important ways. First, by demonstrating that occupational activity levels are important health predictors, we offer an explanation for the puzzling situation in India where increases in weight coexist with overall declines in energy intake levels. Although intake levels may have declined, the aggregate occupational structure of the economy appears to have transitioned to a more sedentary profile that accompanies general structural development over time. In consequence, individuals continue to be net consumers of energy. Second, by creating a mapping of occupations and metabolic equivalent values (discussed

\footnotetext{
${ }^{2}$ The literature from developed countries is more mixed. Lakdawallah and Philipson (2002) using data from the US find that a woman who spends one year in the least physically demanding job has a significantly higher weight as compared to a woman who spends a year in the most physically demanding job. He and Baker (2004), however, find no statistically significant relationship between light or vigorous physical activity in the workplace and weight gain in the US. Using data from Finland, Bockerman, et al. (2008) finds that a man weighs lower when his occupation is physically demanding compared with men involved in sedentary jobs. Sarma, et al. (2014) using data from Canada find that both leisure time physical activity and work related physical activity are associated with a reduction in BMI, and the effects are stronger for women than for men. Gender-disaggregated impacts are also found in Abramowitz (2016) where the association between time spent in work and BMI is most pronounced in non-strenuous jobs. Comparing BMI of men and women in developed and developing countries leads to what has been termed the gender BMI puzzle (see for example Maruyama and Nakamura (2018)). Regardless of the average BMI level of each country, the average female BMI is higher than the average male BMI in developing countries, while the opposite is true in developed countries.
} 
below), we provide a more comprehensive measure of the intensity of work profiles in India than has been done before.

\section{Data and construction of the estimation sample}

Our analysis is conducted using nationally representative data from two waves of the India Human Development Survey (IHDS) conducted in 2004-05 (henceforth referred to as the IHDS1) and 2011-12 (henceforth referred to as the IHDS2). The survey collected information on health, education, employment, economic status, marriage, fertility, gender relations, and social capital. While both rounds of the survey collected anthropometric data for women, the corresponding data for men was collected systematically only in 2011. In this paper, we concentrate on the repeated cross-sectional aspect of the data. This is because panel estimations require adequate variation in measures of labor market engagement in order to evaluate their effects on weight outcomes. However, given the relatively short 5 to 6 year gap, we find that up to $90 \%$ did not change occupations across rounds of the IHDS. ${ }^{3}$

We use Body Mass Index (BMI) as our indicator of weight. BMI, defined as the ratio of weight (in kilograms) to height (in meters) squared is commonly accepted as a key indicator of weight. BMI can be used to categorize individuals into different weight categories: underweight (BMI < 18.5), normal weight $(\mathrm{BMI} \in[18.5,25))$, overweight $(\mathrm{BMI} \in[25,30))$, obese $(\mathrm{BMI} \in[30,40))$ and morbidly obese (BMI $\geq 40){ }^{4}$ We highlight these indicator categories for illustrative purposes only. Our paper uses the continuous measure of BMI as it is more robust, and in order to avoid taking a stance on which cut-offs are more appropriate.

\footnotetext{
${ }^{3}$ Roemling and Qaim (2013) also do not use the panel aspect of the Indonesian data for similar reasons.

${ }^{4}$ These general cut-offs might not be appropriate for the Asian population: in particular, Asian populations have been found to have different associations between BMI, percentage of body fat and health risks, as compared to the European population (see WHO (2004)).
} 
The primary focus of our analysis is working men and women 18-60 years old residing in urban areas of India. We exclude the sample of individuals who have not worked in the one year prior to the survey (i.e., non-working men and women). It is well understood that the sample of people who work is systematically different from the sample of people who do not work, that is, the working population is non-random. Selection into work could be driven by ability for example, as more able people tend to be better educated and thus more suited to remunerative occupations in the labor market. Comparing individuals within the working sample however is less susceptible to this problem. Moreover, it is not clear what metabolic equivalent values should be assigned to those who are not engaged in the labor market (there is no equivalent metabolic scale for those who do not work). Rather than combine disparate populations and use arbitrarily assigned metabolic equivalent values for those absent from the labor market, we restrict our main analysis to only those who work. We justify this decision in three ways. First, we find that BMI in the first round does not predict withdrawal from the labour market in the second round, i.e., the decision to work is independent of lagged weight status. We describe these results in detail below. Second, the cumulative density functions of BMI for those who work and do not work appear to be statistically indistinguishable. Again, we discuss these figures in detail below. Third, depending on the definition of work used, between $79-83 \%$ of women and $23-28 \%$ of men do not work. We compare the results for the working sample to those for the full sample (i.e., including those that were not engaged in the labour market in the previous year). The two sets of results are similar. We do, however, recognize that our results are not universally applicable in terms of policy given that we restrict our main analysis to the working population.

Both the IHDS1 and the IHDS2 surveys contain information on whether any household member worked on farms, worked for payment (wage/salary), or worked for a household business during the 12-month period preceding the survey. Also included are questions on the type of occupation/business, number of days worked in the preceding year, and hours worked in a day in 
each occupation. ${ }^{5}$ Using this, we compute total hours worked in the preceding year which is the sum of hours spent working on farms, household business and for wage/salary. ${ }^{6}$ We use two definitions of work. First, we define an individual to be employed if he/she is involved in an economic activity for the majority of the year. We aggregate the number of days worked across all categories to get the total number of days worked in the preceding year. An individual is considered to be employed if he/she worked for at least 180 days in the preceding year. This is Definition 1. This is similar to the usual principal status definition used by the National Sample Surveys of India (NSS). ${ }^{7}$ In the second definition of work, an individual is considered to be employed if hours worked in the preceding year were at least 240 hours. This is Definition 2 (the IHDS definition of work). We use two definitions of work to demonstrate the robustness of our results: our estimates are broadly consistent irrespective of the definition used.

We define intensity of work in a number of ways. Our first measure of intensity is an individual's sector of work. We use the two-digit National Classification of Occupation (NCO) codes to identify the type of occupation associated with the primary activity - defined as one in which an individual spent maximum time in the preceding year. Following the approach adopted by Fletcher and Sindelar (2009), we classify these occupations into white and blue-collar jobs. White-collar jobs are generally not physically strenuous and include professionals, technical or administrative workers, executives, managers and clerical workers. Blue-collar jobs are more

\footnotetext{
${ }^{5}$ Within the wage/salary category, there are individuals who report working in more than one job. IHDS2 collected information on number of days worked, hours worked in a day, and type of occupation for all jobs an individual is engaged in. IHDS1 collected information only for one job. Since the proportion of individuals in urban areas who have more than one job is very low in both rounds, to maintain consistency, we exclude individuals who work in more than one job within the wage/salary category. In consequence we drop 136 men and 84 women in the IHDS2 data and 19 women in the IHDS1 data to arrive at our estimating sample.

${ }^{6}$ If a household had more than one type of business, information on the other type was included. In total, three household business types were included in the questionnaire. If the individual worked on multiple businesses, total time spent in household business was computed as the aggregate of hours spent in the three businesses. To compute the hours spent in an activity in the preceding year, we multiplied the days worked in the preceding year in that activity by the (average) hours spent in a day on that activity.

${ }^{7}$ Unlike the NSS definition of principal status, in Definition 1 we condition on the number of days. We use 180 days as an approximation of at least $50 \%$ of days worked in a year which is similar to the "major time criterion" used by NSS to define work status.
} 
physically demanding and include individuals working in agriculture, manufacturing, sales and those classified as service workers (such as maids, sweepers, and protective service workers such as policemen or military personnel). Table A1 presents details on the categorization of occupations.

We use the occupation code associated with the primary activity of the individual to obtain a second classification of occupations: low, medium or high activity. Under this categorization (which follows Colchero, et al. (2008)), all white-collar jobs are classified as low activity occupations. Blue-collar jobs were demarcated into medium activity occupations (sales and service workers and those in transport and communications) or high activity occupations (production workers, those in construction work). Table A1 in the Appendix provides further details on these classifications.

To measure intensity or physical strenuousness of work, we follow Tudor-Locke, et al. (2011) and assign each occupation a corresponding Metabolic Equivalent (MET) value. METs are commonly used for evaluating the energy expenditure of a specific activity. The MET of an activity is the ratio of the rate of energy expenditure during the activity to the rate of energy expenditure at rest (one MET is the energy it takes to sit quietly or be at rest). Hence an individual engaged in an activity with a MET value of 4 expends 4 times the energy used by the body at rest. Each occupation listed in India's National Classification of Occupations (NCO) at the three-digit level was cross-matched with the 509 detailed occupations in the 2002 Census Occupational Classification System (OCS). We then take the average of MET values of corresponding threedigit codes to arrive at the two-digit level. Aggregation to this level is necessary as the IHDS data identifies occupations at the more composite two-digit level. Table A2 in the Appendix presents details on the MET values assigned to each occupation. Following Tudor-Locke et al. (2011), we further categorize activities into three indicators of intensity levels: light (MET < 3.00), moderate $(\mathrm{MET} \in[3.00-6.00))$ and vigorous (MET $\geq 6.00)$. To ensure that the mapping between sector of 
work and the MET values is sensible, we demarcated each occupation in Table A2 by sector of work and activity levels, and then took the average of MET values by these categorizations. These are reported in Figure A1 in the Appendix. Panel A of this figure show that that the average MET for white collar occupations is 1.87 , compared to 3.23 for blue collar occupations. Panel B of Figure A1 shows that the average METs for those in medium and high activity occupations are 2.78 and 3.42 respectively, both of which are higher than the average MET of 1.87 for those in low activity occupations.

\section{Empirical Framework}

We estimate regressions of the following form:

$$
B M I_{i h t}=\beta_{0}+\beta_{1} \text { Labor Market Activity }_{\text {iht }}+\gamma X_{i h t}+\varepsilon_{i h t}
$$

$B M I_{\text {iht }}$ is the BMI of working individual $i$ residing in household $h$ at time $t$; Labor Market Activity $_{\text {iht }}$ is defined in a number of ways. Specification 1 defines labor market activity as the sector of work: employed in a blue-collar occupation relative to a white-collar occupation. Specification 2 conditions on the individual being employed in a medium or high activity occupation relative to employment in a low activity occupation. Specification 3 uses continuous MET values associated with each occupation. Specification 4 includes dummies for occupations involving moderate and vigorous physical activity (categorizations based on MET values described above) with the reference category being light physical work. $\mathrm{X}_{\text {int }}$ includes a set of individual (age, age square, years of education, marital status, whether or not the individual consumes tobacco, number of children, and the average number of hours spent watching television) and household level controls (dummies for wealth quartiles, whether or not the household has domestic help, whether the household owns a car or a motor cycle, household religion, and the share of total expenditure on eating outside of the home). We include a dummy for 2011-12 (IHDS2 survey) to take into account temporal variations and a set of state dummies to account for any unobserved state specific characteristics (including government policy) that 
could potentially affect BMI. ${ }^{8}$ The regressions for working women are run on the sample that does not report being pregnant, and working men and women are restricted to be in the prime working age of 18-60 years. Standard errors are clustered at the state level.

\section{Descriptive Statistics}

Summary statistics on the work definitions and categories defined above are shown in Table 1.

Columns 1-4 present the sample means for urban working women and men aged 18-60; columns 5-8 the corresponding sample means for the married sample of women and men.

Consider the sample of urban working women and men of prime age. We begin by discussing patterns for women. The first two columns of Table 1 shows that conditional on working and depending on the definition of work used, $36-41 \%$ of women work in white-collar occupations. Table 1 reports that around $36 \%$ of women are in high activity jobs under Definition 1 . The corresponding proportion under Definition 2 is about 43\%. Since all white-collar work is classified as low activity, about $36-41 \%$ of women are in such occupations.

Average BMI levels are higher for women employed in white-collar occupations than those in blue-collar occupations $\left(24.26 \mathrm{~kg} / \mathrm{m}^{2} \mathrm{vs} 22.75 \mathrm{~kg} / \mathrm{m}^{2}\right)$, and higher among those engaged in low activity occupations than those in high activity occupations $\left(24.26 \mathrm{~kg} / \mathrm{m}^{2} \mathrm{vs} 22.64 \mathrm{~kg} / \mathrm{m}^{2}\right)$. The kernel density results presented in Panel A of Figure 1 show that the distribution of BMI of urban women working in white collar occupations is statistically distinct as compared to that of urban women working in blue collar occupations. ${ }^{9}$ Figure 2 presents the distribution of BMI by activity level of occupation. Panel A shows that the distribution of BMI for those urban working in low

\footnotetext{
${ }^{8}$ We are unable to include the 2011 dummy for the regressions for men as BMI data for men are only available in the IHDS2 survey as we note in detail below.

${ }^{9}$ Kolmogorov-Smirnov (K-S) test p-value $=0.00$, for both Definitions 1 and 2 .
} 
activity occupations is measurably different as compared to the BMI of those in medium and high activity occupations. ${ }^{10}$

Figure 3 presents the non-parametric Lowess plots of the relationship between the intensity of work (MET value) and BMI for urban working women of prime age. Panel A shows that for MET values of less than or equal to 2 , an increase in intensity is weakly associated with changes in BMI. Beyond this range however, an increase in the strenuousness of occupations is associated with a systematic and substantial decline in BMI as expected.

Conditional on being employed, 64-70\% of urban women are employed in light intensity occupations; the proportion declines to 5-8\% for vigorous intensity occupations. As expected, the average BMI of women working in light intensity occupations is greater than those employed in high intensity occupations $\left(23.73 \mathrm{~kg} / \mathrm{m}^{2}\right.$ vs $22.15 \mathrm{~kg} / \mathrm{m}^{2}$ under Definition 1 ; the difference is marginally wider under Definition 2). Panel A of Figure 4 corroborates these patterns. The distribution of BMI of women working in light intensity occupations stochastically dominates the BMI of women in moderate and vigorous intensity occupations. ${ }^{11}$

Turning to men, the descriptive statistics presented in columns 3-4 of Table 1 show men aged 18-60 are considerably more likely to be engaged in the labor market as compared to women, with only $23-28 \%$ of men in the sample reporting not working. Conditional on working, $37-38$ $\%$ of men are employed in white collar occupations and $41-43 \%$ are engaged in high activity work. As with the sample of women, across both definitions of work, those employed in whitecollar occupations and those in low activity occupations have higher BMI compared to those in

\footnotetext{
${ }^{10}$ For Definition $1, \mathrm{~K}-\mathrm{S}$ test p-values for equality of distributions are $0.00,0.00$ and 0.01 for the low and high, low and medium, and medium and high activity occupations respectively. For Definition 2, the corresponding K-S test p-values are $0.00,0.00$ and 0.00 .

${ }^{11}$ For Definition 1, K-S test p-values for equality of distributions are $0.00,0.00$ and 0.15 for the light and heavy, light and moderate, and moderate and vigorous intensity occupations, respectively. For Definition 2 , the corresponding K-S test p-values are $0.00,0.00$ and 0.03 .
} 
blue-collar occupations $\left(24.20 \mathrm{~kg} / \mathrm{m}^{2}\right.$ vs $\left.23.03 \mathrm{~kg} / \mathrm{m}^{2}\right)$ and those in high activity occupations $\left(24.20 \mathrm{~kg} / \mathrm{m}^{2}\right.$ vs $\left.22.81 \mathrm{~kg} / \mathrm{m}^{2}\right)$, respectively.

The sample statistics presented in columns 3-4 of Table 1 are corroborated by the kernel density estimates presented in Panel B of Figures 1,2 and 4. The mass of the distribution of BMI for working men engaged in white-collar occupations, in low activity occupations and light intensity occupations lies to the right of that for those employed in blue-collar occupations, in high activity occupations and in vigorous intensity occupations, respectively. ${ }^{12}$ The Lowess plots of BMI on intensity of occupation presented in Panel B of Figure 3 show that for a wide range of MET values for men, there is the expected negative relationship between BMI and occupational intensity. This pattern weakly changes in the case of relatively high MET values. This is possibly driven by the presence of outliers or the paucity of observations at these higher ranges of MET.

\section{Focus on the Working Population}

The main analyses of this paper focuses on working men and women. We concentrate on the working sample since it is well established in the literature that those who choose to work and those who choose not to work are distinct populations. Moreover, there are no metabolic equivalent values to be assigned to those who do not work. We further justify our decision to concentrate on the working population in three ways. First, in order to ensure that the sample of working individuals is not selected in terms of weight (in case, for example, heavy people choose not to work and exit the labor market), using the panel aspect of the IHDS data, we test to ascertain that BMI in the first round does not predict exit from the working sample in the second round.

\footnotetext{
${ }^{12}$ In Figure 1, Panel B, K-S test p-value for equality of distribution is 0.00 , for both Definitions 1 and 2. In Figure 2, Panel B, for Definition 1, K-S test p-values for equality of distribution are 0.00, 0.00 and 0.01 for the low and high, low and medium, and medium and high activity occupations, respectively. For Definition 2, the corresponding K-S test p-values are 0.00, 0.00 and 0.00. Finally in Figure 4, Panel B, for Definition $1, \mathrm{~K}-\mathrm{S}$ test p-values for equality of distribution are $0.00,0.00$ and 0.65 for the light and vigorous, light and moderate, and moderate and vigorous intensity occupations, respectively. For Definition 2, the corresponding K-S test p-values are $0.00,0.00$ and 0.57 .
} 
We are able to conduct this test only for urban working women since, as noted above, the panel component of the anthropometric data is absent for men. These results are presented in Table 2. As is evident, BMI in the first round is not associated with exit from the labour market in the second round. Hence the sample of working women is not selected by virtue of non-random attrition (driven by weight).

Second, we present the cumulative density functions (CDF) for the BMI distributions for the working population against the non-working population. The idea here is to examine whether by focusing on only the working population, we inadvertently restrict our analysis to a specific, nonrepresentative part of the overall BMI distribution. These CDF plots are reported in Panel A for working women and Panel B for working men in Figure 5. For women, there is little evidence that the distributions are statistically distinct, particularly for Definition 1 (our primary definition). ${ }^{13}$ In other words, by restricting our analysis to the working sample only, we are not curtailing the support of the overall BMI distribution. Third, as a robustness check, we also report results for the full sample that includes men and women aged 18-60 who were not engaged in the labour market in the previous year. As we discuss in detail below, the two sets of results are similar.

\section{Regression Results}

\subsection{Urban working women. OLS regressions}

The ordinary least squares (OLS) regression results that correspond to equation (1) are presented in Table $3 .{ }^{14}$ As Definition 1 is consistent with the National Sample Statistical Organization (NSS) of India's definition of work, we label those results as primary (results with Definition 2 are broadly the same). The primary OLS results are presented in the columns $1-4$ of Table 3 .

\footnotetext{
${ }^{13} \mathrm{~K}$-S test p-value $=0.12$ for Definition 1 and 0.00 for Definition 2 .

${ }^{14}$ Table 3 reports results for the key variables of interest. Results for all variables used as controls in these regressions are reported in Table B1 in the Appendix.
} 
We begin by discussing results for urban working women (Panel A in Table 3). The estimates in column 1 of Table 3 show that relative to women working in white collar occupations, BMI is significantly lower for those working in blue collar occupations. The effect is fairly large. The coefficient estimate indicates that on an average, BMI among women working in blue collar occupations is a statistically significant $0.44 \mathrm{~kg} / \mathrm{m}^{2}$ lower compared to those working in white collar occupations. Given that the average BMI of women working in white collar occupations is $24.26 \mathrm{~kg} / \mathrm{m}^{2}$, this is a $1.85 \%$ decline. Estimates presented in column 2 of Table 3 show that relative to those working in low activity occupations, the BMI of those working in medium activity occupations is $0.29 \mathrm{~kg} / \mathrm{m}^{2}$ (or $1.20 \%$ ) lower, while the BMI of those working in high activity occupations is $0.54 \mathrm{~kg} / \mathrm{m}^{2}$ (or $2.23 \%$ ) lower, with the latter coefficient estimated precisely. The BMI of those working in medium activity occupations is larger in magnitude than those in high activity occupations; however, this difference is not statistically significant under Definition 1.

The results presented in column 3 of Table 3 show that any increase in MET is associated with a decline in BMI: a one-unit increase in MET is associated with a $0.26 \mathrm{~kg} / \mathrm{m}^{2}$ reduction in BMI. The regressions presented in column 4 show that relative to those working in light intensity occupations, the BMI of those in moderate intensity occupations is $0.37 \mathrm{~kg} / \mathrm{m}^{2}$ or $1.56 \%$ lower (not statistically significant) and the BMI of those in vigorous intensity occupation is a statistically significant $0.80 \mathrm{~kg} / \mathrm{m}^{2}$ or $3.37 \%$ lower. Those in moderate intensity occupations have a higher BMI relative to those in vigorous activity occupations although the difference is imprecisely estimated.

Columns 5-8 of Table 3 repeat these specifications for Definition 2. These results are consistent with those obtained under Definition 1 and we do not discuss them in detail. 


\subsection{All urban women. OLS regressions.}

As a robustness check for our estimates that restrict the sample to the working population, we reestimate columns 1, 2, 5 and 6 in Table 3 using the full sample of individuals that includes those who do not work. Sector of occupation now has three possibilities: not working, employed in a white-collar occupation, or employed in a blue-collar occupation. Activity levels now have four possibilities: not working, employed in a low activity occupation, employed in a medium activity occupation, or employed in a high activity occupation. We cannot re-estimate the specifications in columns 3, 4, 7 and 8 of Table 3 as MET values are undefined for those who do not work. The results reported in panel A of Table 4, resonate with those in Panel A of Table 3. In particular, under both Definition 1 and Definition 2, blue collar work (relative to not working) carries with it a BMI penalty, as does work in medium and high activity occupations (again, relative to not working): relative to those not working, those working in white collar occupations have a $0.94 \%$ lower BMI (though not significant) while those working in blue collar occupations have a $2.39 \%$ lower BMI (see column 1 of Table 4). Similarly the results in column 2 show that relative to those not working, those in low (imprecisely estimated), medium and high activity occupations have a $0.94 \%, 1.68 \%$ and $2.87 \%$ lower BMI.

\subsection{Urban working women. IV regressions}

It is possible that labor market activity is correlated with the unobserved determinants of BMI, that is, the sector of occupation may be endogenous. This could be due to reverse causality as heavier women may choose more sedentary occupations or there could be unobserved variables that simultaneously affect both BMI and labor market activity. For example, there might be individual specific unobserved heterogeneity: genetic or motivational disposition that affects both labor market engagement and weight. Examples of this include differences in (hard to quantify) health or psychological conditions that affects weight, and also occupational choices made in the labor market. In the presence of sorting into occupational categories, OLS is likely to underestimate the effect of labor market engagement on BMI. So, if selection into blue collar 
work is driven by lack of education, or if those in blue collar work tend to be less endowed with health (as a cause or a consequence of being in this strata of work), then there is sorting. Consequently, on average, those in blue collar jobs may be of lower BMI to begin with as compared to the average worker in the sample. OLS reflects this sorting and reports estimates that are contaminated with a negative bias. Alternatively, incentives for physical activity, transportation choices and exercise might align differently by sector of work, and these unobserved (to the researcher as data on these are unavailable) preferences could also lead to a negative bias. The IV estimates however, which are free of this bias, should thus be comparatively larger. Hence due to unobservable differences that vary systematically between those who select into distinctive occupational sectors, OLS underestimates the effect of labor market engagement on BMI.

In light of the above, we conduct IV regressions that account for potential unobservables of this nature by instrumenting the sector of work (blue-collar or white-collar) and the intensity of work (measured by MET values). The instruments we use include the ability to speak English (fluently or moderately) and spouse's occupational activity level. Azam, et al. (2013) demonstrates using the IHDS1 data set that the ability to speak English fluently (or even moderately) is strongly correlated with higher earnings. We contend that the ability to speak English is positively correlated with the likelihood of working in a white-collar occupation. The second instrument we propose is spouse's occupational activity level. Positive assortative matching in the marriage market implies that spouses often have similar levels of education, which implies that spouse's occupational activity level is likely to be correlated with the index individual's occupational level of activity (Siow (2015)).

Our choice of instruments requires that we restrict the sample in the IV regressions to the married sample. While this reduces the sample size slightly, summary statistics for work patterns and BMI by sector of work, work activity and intensity of work remain similar to the full sample (see 
columns 5-8 of Table 1). The OLS estimates of the effect of labor market engagement on BMI for those who are married are presented in columns 1 and 3 of Table 5 which considers sector of work, and columns 1 and 3 of Table 6 which considers labour market intensity. A comparison of the corresponding columns in Tables 3 and Tables 5 and 6 shows that while not identical, the estimates for the married and working sample are in the same ballpark as those for the working sample. Given this, we do not discuss the OLS results in Tables 5 and 6 further at this stage.

Table A3 in the Appendix presents the first stage results. The coefficients on the instruments are of the expected sign and the reported first stage F-statistics are greater than the conventionally accepted threshold of 10 in all cases. This is corroborated by the Cragg-Donald Wald F-statistic (not reported in table) which exceeds the 5\% maximal IV relative bias (using the critical values defined by Stock and Yogo (2005)). Hansen's $J$ statistic does not reject the null that the instruments are valid at 5\% across all columns in this table. Hence these instruments pass the conventional tests of relevance and validity.

For the instruments to be valid instrument, we require that the instruments (spoken English skills and the occupational activity of the spouse) do not have a direct effect on the particular individual's BMI, conditional on labour market sector and intensity of work, as well as all other individual and household controls i.e., they do not violate the exclusion restriction. We reestimated equation (1) including spoken English ability and occupation of spouse as additional variables. The regression results presented in Table A4 show that neither the ability to speak English nor the occupation of the spouse has a significant effect on BMI. ${ }^{15}$

\footnotetext{
${ }^{15}$ The corresponding results for men are similar save for a single specification.
} 
The IV results for women are presented in columns 2 and 4 in Panel A of Table 5 for sector of work and Table 6 for intensity of work. ${ }^{16}$ The IV estimates are larger than the corresponding OLS estimates indicating that OLS underestimates the effect of occupational choice on BMI.

The IV regression estimate in column 2 of Table 5 implies that relative to those working in whitecollar occupations, working in a blue-collar occupation results in a $1.01 \mathrm{~kg} / \mathrm{m}^{2}$ or $4.12 \%$ decline in BMI for our primary result using Definition 1. This implies that on average women working in blue-collar occupations are 2.7 kilograms (kgs) or 6 pounds lighter than women working in whitecollar occupations. The corresponding difference based on Definition 2 is about $2.2 \mathrm{kgs}$ or about 5 pounds. Turning to the results for labor market intensity in Table 6 next, the IV estimates in columns 2 and 4 are also larger compared to the corresponding OLS estimates in columns 1 and 3. The instrument results indicate that a unit increase in MET results in a $0.51 \mathrm{~kg} / \mathrm{m}^{2}$ decrease in BMI under Definition 1. The corresponding IV estimate using Definition 2 is $0.64 \mathrm{~kg} / \mathrm{m}^{2}$. These results in Table 6 are thus consistent with those in Table 5 in indicating that labor market activity levels significantly drive individual weight measures - more physically exertive and intense work is systematically associated with lower BMI.

As further checks for the robustness of these results, we control for the share of total household expenditures on a range of diet related variables including sugar in all regressions. We find that our key OLS and IV results remain unaffected (results available on request). Further, in order to ascertain that the results are not being driven by non-linearities in income and education, we replaced household wealth quantiles with household expenditure per capita, its squared term and its cubed term (keeping all other controls the same). Again, our key OLS and IV results remain unchanged (results available on request).

\footnotetext{
${ }^{16}$ The full set of results are presented in Table B2 in the Appendix.
} 


\subsection{Urban Working Men. OLS regressions}

The OLS regression results for the sample of working men aged 18-60 are presented in Panel B of Table 3 (columns 1-4 and 5-8 for Definitions 1 and 2, respectively). Relative to those working in white-collar occupations, men working in blue-collar occupations have a $0.33 \mathrm{~kg} / \mathrm{m}^{2}$ lower BMI (see column 1). Given that the average BMI for men employed in white-collar occupations is $24.20 \mathrm{~kg} / \mathrm{m}^{2}$, this implies that men employed in blue-collar occupations are $1.36 \%$ lighter. The results presented in column 2 imply that relative to those working in low activity occupations, men working in high activity occupations have a $2.05 \%$ lower BMI (difference is statistically significant). An increase in MET is associated with a systematic decline in BMI (column 3). However, consistent with the patterns presented in the Lowess plots for the relationship between BMI and intensity of occupation (Panel B of Figure 3), the impact is statistically weak. Relative to men working in light intensity occupations, although those in moderate intensity occupations have BMI that is $0.28 \mathrm{~kg} / \mathrm{m}^{2}$ lower; the coefficient for those in vigorous intensity occupations is statistically zero. Results for Definition 2 for men mostly echo these findings. ${ }^{17}$

\subsection{All urban men. OLS regressions}

As in the case for women, we re-estimate columns 1,2, 5 and 6 in Table 3 using the full sample of men that includes those who do not work. These results are presented in Panel B of Table 4 and are broadly consistent with those reported for men in Table 3. In particular, under both Definition 1 and Definition 2, blue collar work (relative to not working) results in lower BMI as does work in high activity occupations (again, relative to not working). Focusing on differences in particular, those in columns 1 and 3 between blue collar and white collar work are significant. This is also true for differences between high and low activity work and high and medium activity work under Definition 1 in column 2, and between both high and low activity and high and medium activity work under Definition 2 in column 4.

\footnotetext{
${ }^{17}$ Table B3 reports results for the full set of variables used as controls in these regressions.
} 


\subsection{Urban Working Men. IV regressions}

Consistent with the results for women, the IV regression results for men presented in columns 2 and 4 in Panel B of Tables 5 and 6 are larger than the corresponding OLS estimates, reflecting, for reasons outlined above, the negative bias in the OLS estimates. ${ }^{18}$ The IV estimate in column 2 of Table 5 implies that relative to those working in white-collar occupations, working in a bluecollar occupation results in a $1.18 \mathrm{~kg} / \mathrm{m}^{2}$ or $4.81 \%$ decline in BMI for our primary Definition 1. This implies that on average men working in blue-collar occupations are $3.2 \mathrm{kgs}$ (or 7 pounds) lighter than those in white-collar occupations. The IV estimate in column 4 of Table 5 indicates that based on Definition 2, the decline is about $2.5 \mathrm{kgs}$ or about 8 pounds. Turning to the results for labor market intensity for men in Table 6 next, the IV estimates in columns 2 and 4 are larger as compared to the corresponding (insignificant) OLS coefficients reported in columns 1 and 3. Estimates indicate that a unit increase in MET results in a $0.65 \mathrm{~kg} / \mathrm{m}^{2}$ decrease in BMI under Definition 1. The corresponding IV estimate using Definition 2 is $0.63 \mathrm{~kg} / \mathrm{m}^{2}$.

The IV estimates of men presented in column 2 and 4 of Tables 5 and 6 include only those with working spouses (wives). Since sample sizes in Tables 5 and 6 and those in Table 3 varied by a margin under this design, we re-estimated the IV regressions for men such that they included nonworking spouses. These results are presented in Table A5. It is clear that including non-working spouses increases the sample sizes, the IV results remain in the same range, and the first stage Fstatistic exceeds the conventionally accepted threshold level. ${ }^{19}$

\section{Conclusion and Policy Implications}

Excess weight, generally considered a problem of richer countries, is now a growing concern in many developing countries. It has been argued that reductions in physical activity commensurate

\footnotetext{
${ }^{18}$ The full set of results are presented in Table B4 in the Appendix.

${ }^{19}$ However, Hansen's $J$ overidentification test is weaker now: we cannot reject at the $5 \%$ level in two cases.
} 
with modest declines in energy intake are crucial factors that underline this rise in over-nutrition. Using data on labor market engagement and its intensity, this study shows that the occupational distribution of work is an important explanatory factor for unhealthy weight levels.

Decreasing employment in agriculture and a general trend towards a service sector economy imply lower physical occupational activity, a process that is occurring at a rapid pace in many developing countries (Monda, et al. (2007)). Technological innovations and growing incomes have made domestic activities and the work place less active. From a health perspective, understanding the relationship between physical activity and excess weight is of considerable importance. However, empirical evidence on this relationship is limited. Our research bridges this gap by analyzing the relationship between physical strenuousness of work and BMI. Taking the potential endogeneity of labor market activity into account, we find that engagement in sedentary jobs is causally (positively) associated with increases in BMI for urban working adults of prime ages.

Given these findings, policies designed to tackle behavioral risk factors closely linked with excess weight, such as physical inactivity and diet, are indispensable. These policies may include communication programs that disseminate information on how grave the issue of overweight and obesity is, and spread awareness about the benefits of physical activity in daily routines. Examples include facilitating the ease of walking to work, encouraging the use of public transportation, or employer-sponsored subsidies for gym membership. Towards this aim, community wide campaigns may be a powerful tool (CDC (2011)).

Local governments can be key players in creating an environment which is more conducive to physical activities through their land use policies for example; these authorities can set requirements for builders to provide parks and recreational facilities in new developments. Lack 
of access to neighborhood parks, recreational facilities, and absence of safe and secure environments may deter women in particular from being more physically engaged. Rectifying this would be a step in the right direction. These are some examples of interventions which may serve to mitigate the unintended health consequences of a torpid workplace. 
ABramowitz, J. (2016): "The Connection between Working Hours and Body Mass Index in the U.S.: A Time Use Analysis," Review of Economics of the Household, 14, 131 - 154.

ADAIR, L. S. (2004): "Dramatic Rise in Overweight and Obesity in Adult Filipino Women and Risk of Hypertension," Obesity Research, 12, 1335-1341.

AZAM, M., A. ChIN, AND N. PRAKASH (2013): "The Returns to English-Language Skills in India," Economic Development and Cultural Change, 61, 335 - 367.

Bell, A. C., K. GE, AND B. M. POPKIN (2001): "Weight Gain and Its Predictors in Chinese Adults," International Journal of Obesity and Related Metabolic Disorders, 25, 1079-1086.

Bockerman, P., E. JohANSSON, P. Jousilahti, AND A. UUTElA (2008): "The Physical Strenuousness of Work Is Slightly Associated with an Upward Trend in the Bmi," Social Science and Medicine, 66, $1346-1355$.

CDC (2011): "Strategies to Prevent Obesity and Other Chronic Diseases: The Cdc Guide to Strategies to Increase Physical Activity in the Community," Atlanta: U.S. Department of Health and Human Services: Centers for Disease Control and Prevention.

Colchero, M. A., B. CABAllero, And D. Bishai (2008): "The Effect of Income and Occupation on Body Mass Index among Women in the Cebu Longitudinal Health and Nutrition Surveys (19832002)," Social Science and Medicine, 66, 1967-1978.

DEATON, A., AND J. DRÈZE (2009): "Food and Nutrition in India: Facts and Interpretations," Economic and Political Weekly, 44, 42 - 65.

EngelgaU, M., A. MAHAL, AND A. KARAN (2012): "The Economic Impact of Non-Communicable Diseases on Households in India," Global Health, 8.

FLETCHER, J. M., AND J. L. SindelAR (2009): "The Effects of Early Occupation on Health," NBER Working Paper 15256.

HE, X. Z., AND D. W. BAKER (2004): "Changes in Weight among a Nationally Representative Cohort of Adults Aged 51 to 61, 1992 to 2000," American Journal of Preventive Medicine, 27, 8 - 15.

LAKDAWALlaH, D., AND T. PHILIPSON (2002): "The Growth of Obesity and Technological Change: A Theoretical and Empirical Investigation," NBER Working Paper \# 8946.

LANCET (2016): "Trends in Adult Body-Mass Index in 200 Countries from 1975 to 2014: A Pooled Analysis of 1698 Population-Based Measurement Studies with 19.2 Million Participants," Lancet, 387, 1377 - 1396.

MAITRA, P., AND N. MENON (2017): "Portliness Amidst Poverty: Evidence from India."

MARUYAMA, S., AND S. NAKAMURA (2018): "Why Are Women Slimmer Than Men in Developed Countries?," Economics and Human Biology, Forthcoming.

Monda, K. L., P. Gordon-Larsen, J. Stevens, And B. M. Popkin (2007): "China's Transition: The Effect of Rapid Urbanization on Adult Occupational Physical Activity," Social Science and Medicine, 64, 858 - 870.

Paeratakul, S., B. M. Popkin, G. Keyou, L. S. AdAIR, AND J. SteVens (1998): "Changes in Diet and Physical Activity Affect the Body Mass Index of Chinese Adults," International Journal of Obesity, 22, $424-434$.

RAMACHANDRAN, P. (2014): "Triple Burden of Malnutrition in India: Challenges and Opportunities," in Idfc Foundation. India Infrastructure Report 2013/14: The Road to Universal Health Coverage: Orient Blackswan.

RoBerts, S. B., AND R. L. LEIBEL (1998): "Excess Energy Intake and Low Energy Expenditure as Predictors of Obesity," International Journal of Obesity and Related Metabolic Disorders, 22, $385-386$.

RoEMLING, C., AND M. QAIM (2013): "Dual Burden Households and Intra-Household Nutritional Inequality in Indonesia," Economics and Human Biology, 11, 563 - 573.

SARMA, S., G. S. ZARIC, M. K. CAMPBELL, AND J. GILLILAND (2014): "The Effect of Physical Activity on Adult Obesity: Evidence from the Canadian Nphs Panel," Economics and Human Biology, 14, 1 - 21.

SIOW, A. (2015): "Testing Becker's Theory of Positive Assortative Matching," Journal of Labor Economics, 33, 409-431.

STOCK, J. H., AND M. YOGO (2005): "Testing for Weak Instruments in Linear Iv Regression," in Identification and Inference for Econometric Models, Essays in Honor of Thomas Rothenberg, ed. by D. W. K. Andrews, and J. H. Stock: Cambridge University Press, New York, 80 - 108. 
TUdor-Locke, C., B. E. Ainsworth, T. L. WASHington, AND R. TROIANo (2011): "Assigning Metabolic Equivalent Values to the 2002 Census Occupational Classification System," Journal of Physical Activity and Health, 8, 581 - 586.

WHO (2004): "Appropriate Body-Mass Index for Asian Populations and Its Implications for Policy and Intervention Strategies," Lancet, 363, 157 - 163. 
Figure 1: Distribution of BMI by sector of occupation Panel A: Urban working women aged 18 - 60

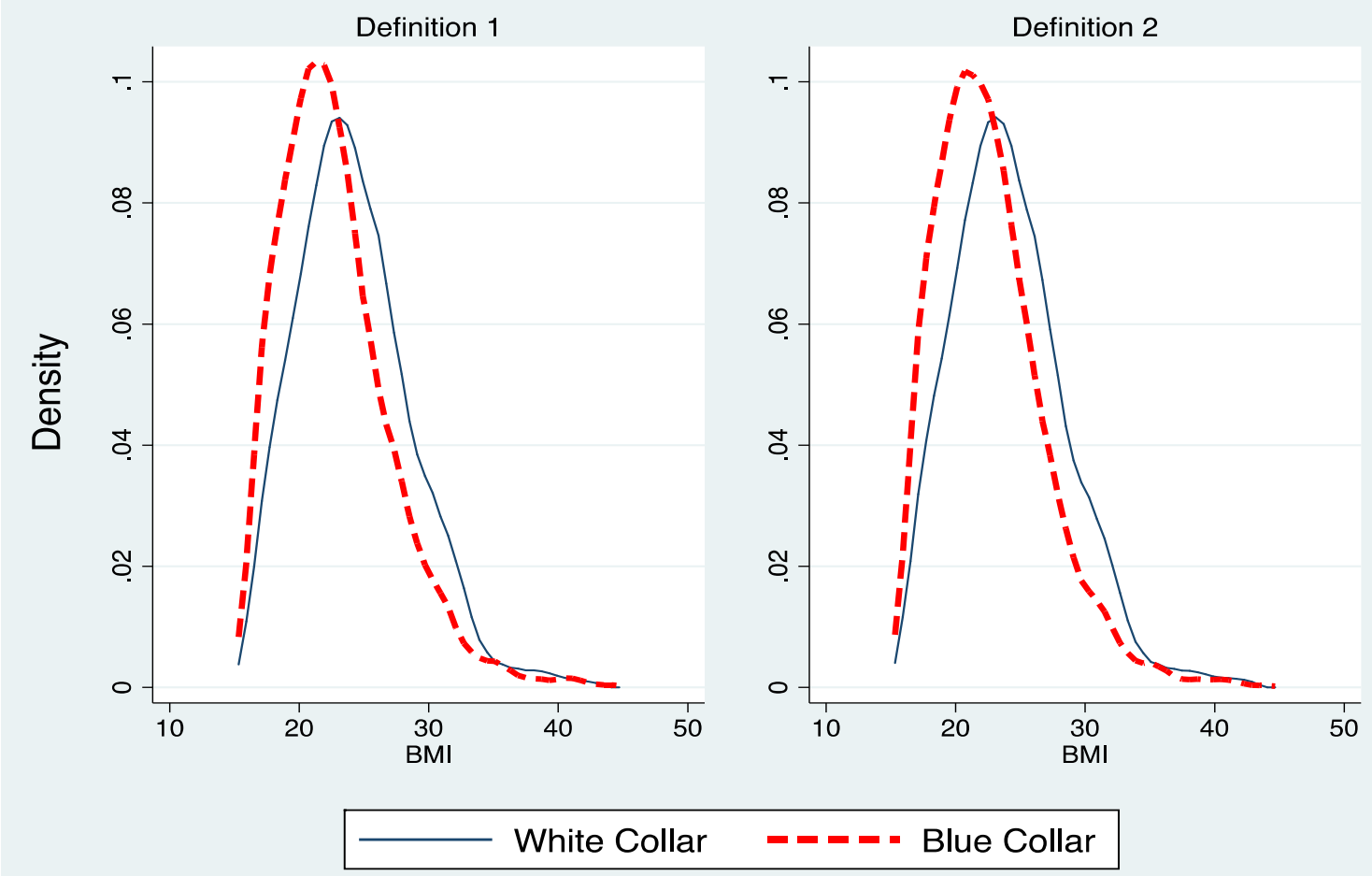

Panel B: Urban working men aged 18 - 60
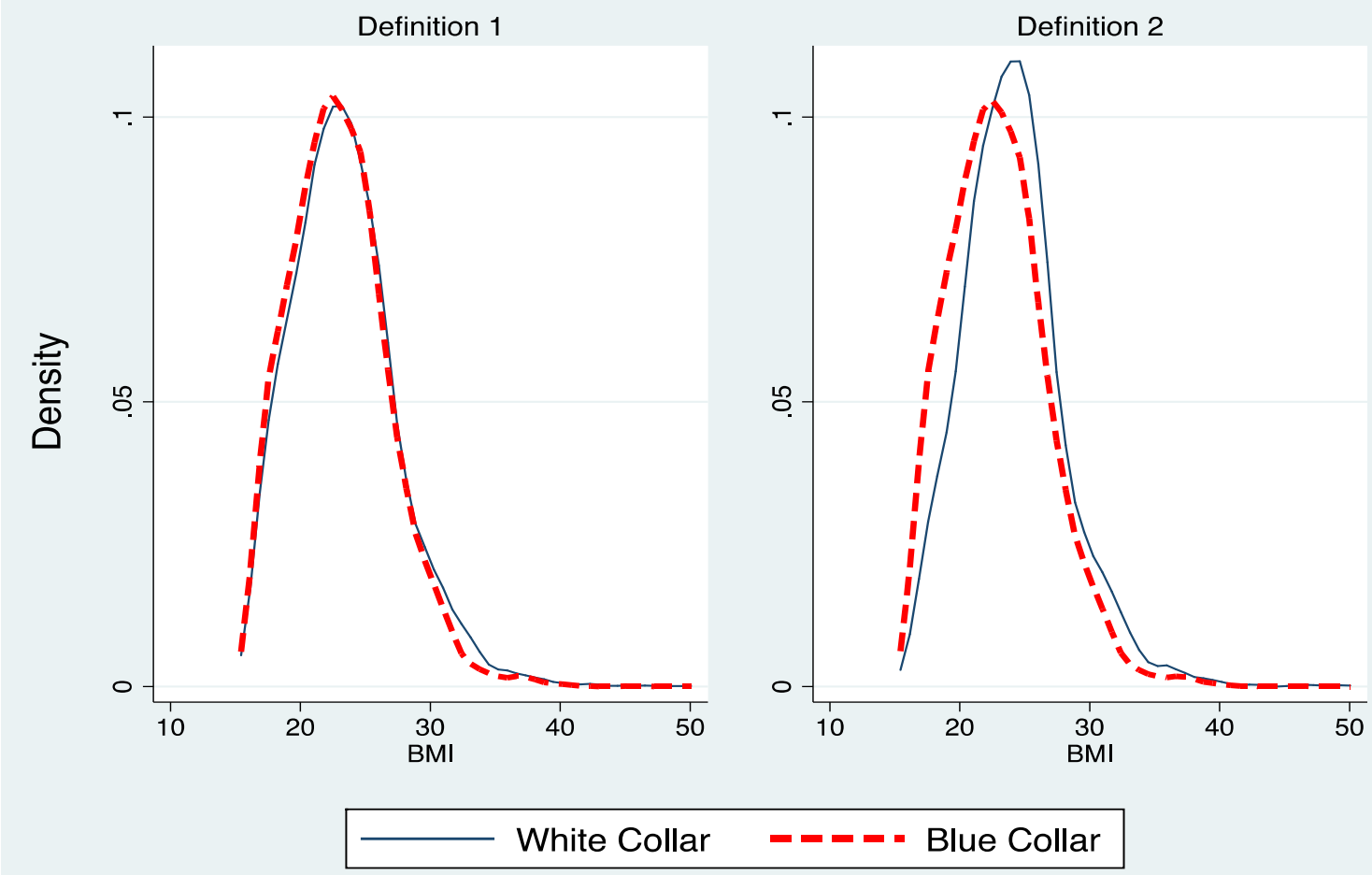

Notes: Kernel Density Estimates of BMI presented. Sample in Panel A restricted to urban working women aged 18 60 in IHDS1 and IHDS2. In Panel B, sample is restricted to urban working men aged 18-60 in IHDS2. See Table A1 for categorization of occupations. Kolmogorov-Smirnov (K-S) test p-value for equality of distribution is 0.00 , for both Definitions 1 and 2, for both women and men. 
Figure 2: Distribution of BMI by activity levels (defined by occupation) Panel A: Urban working women aged $18-60$
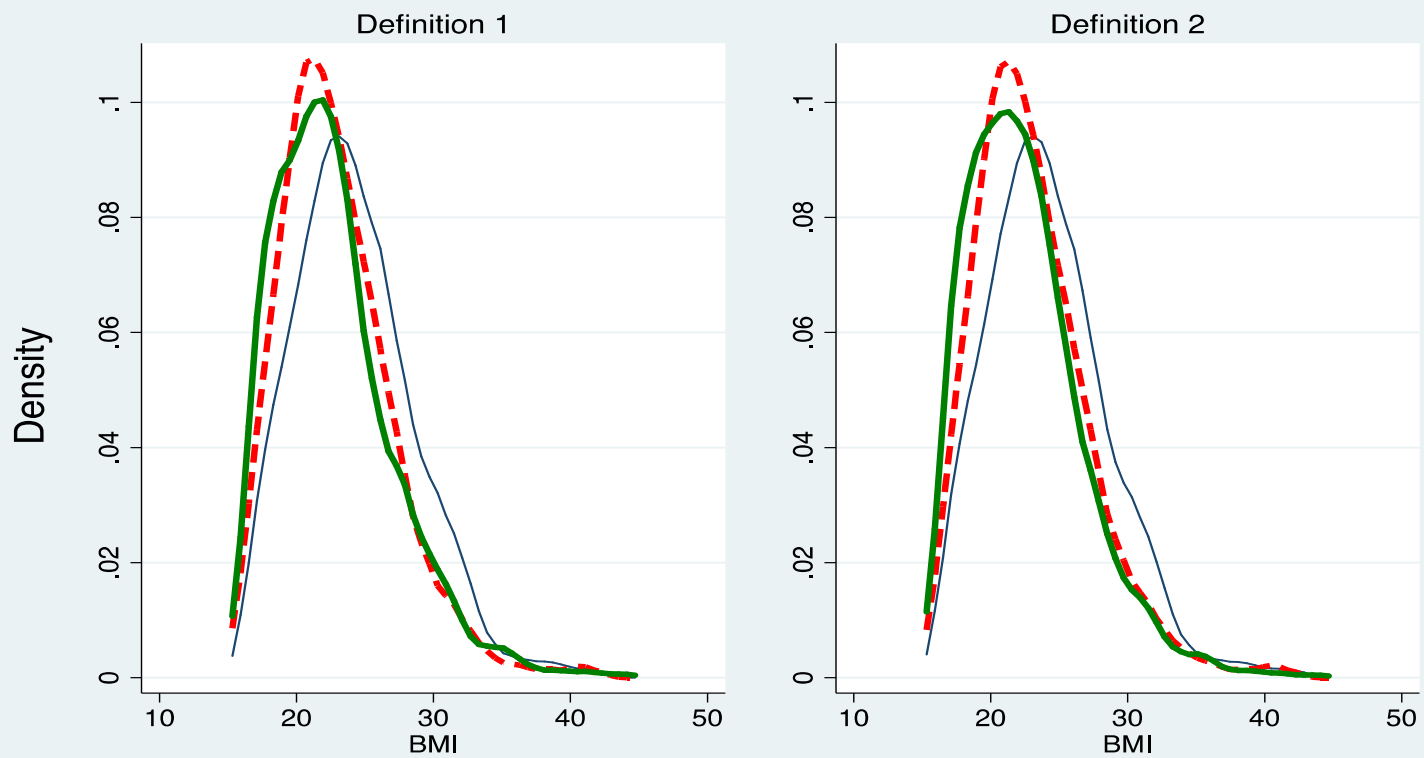

Low Activity

Medium Activity

High Activity

Panel B: Urban working men aged 18 - 60
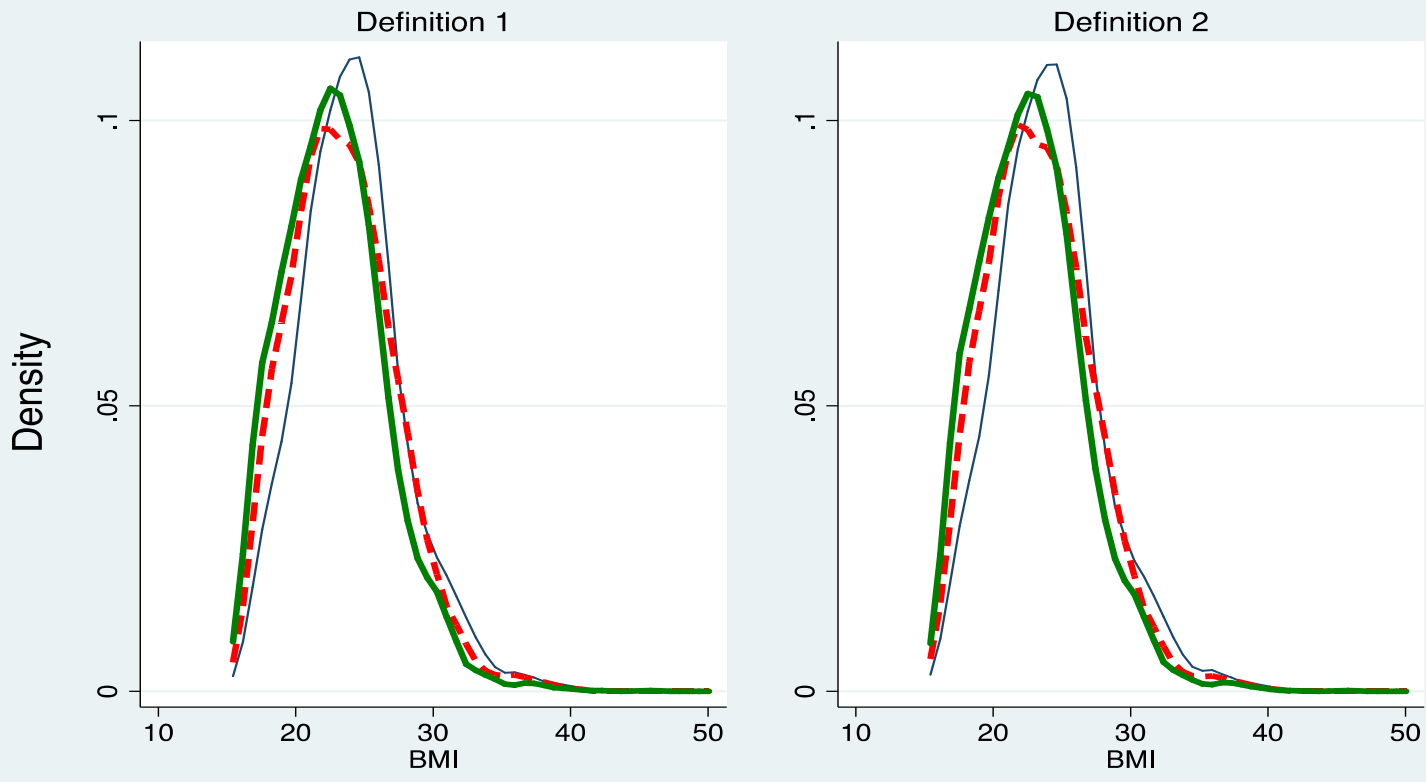

Low Activity

Medium Activity

High Activity

Notes: Kernel density estimates of BMI presented. Sample in Panel A restricted to urban working women aged $18-$ 60 in IHDS1 and IHDS2. In Panel B, sample is restricted to urban working men aged 18 - 60 in IHDS2. See Table A1 for categorization of occupations. In Panel A, for Definition 1, K-S test p-values for equality of distributions are 0.00 , 0.00 and 0.01 for the low and high, low and medium, and medium and high activity occupations, respectively. For Definition 2, the corresponding K-S test p-values are 0.00, 0.00 and 0.00. In Panel B, for Definition 1, K-S test p-values for equality of distributions are $0.00,0.00$ and 0.01 for the low and high, low and medium, and medium and high activity occupations, respectively. For Definition 2, the corresponding K-S test p-values are 0.00, 0.00 and 0.00 . 
Figure 3: Lowess plots of BMI on intensity of activity Panel A: Urban working women aged $18-60$
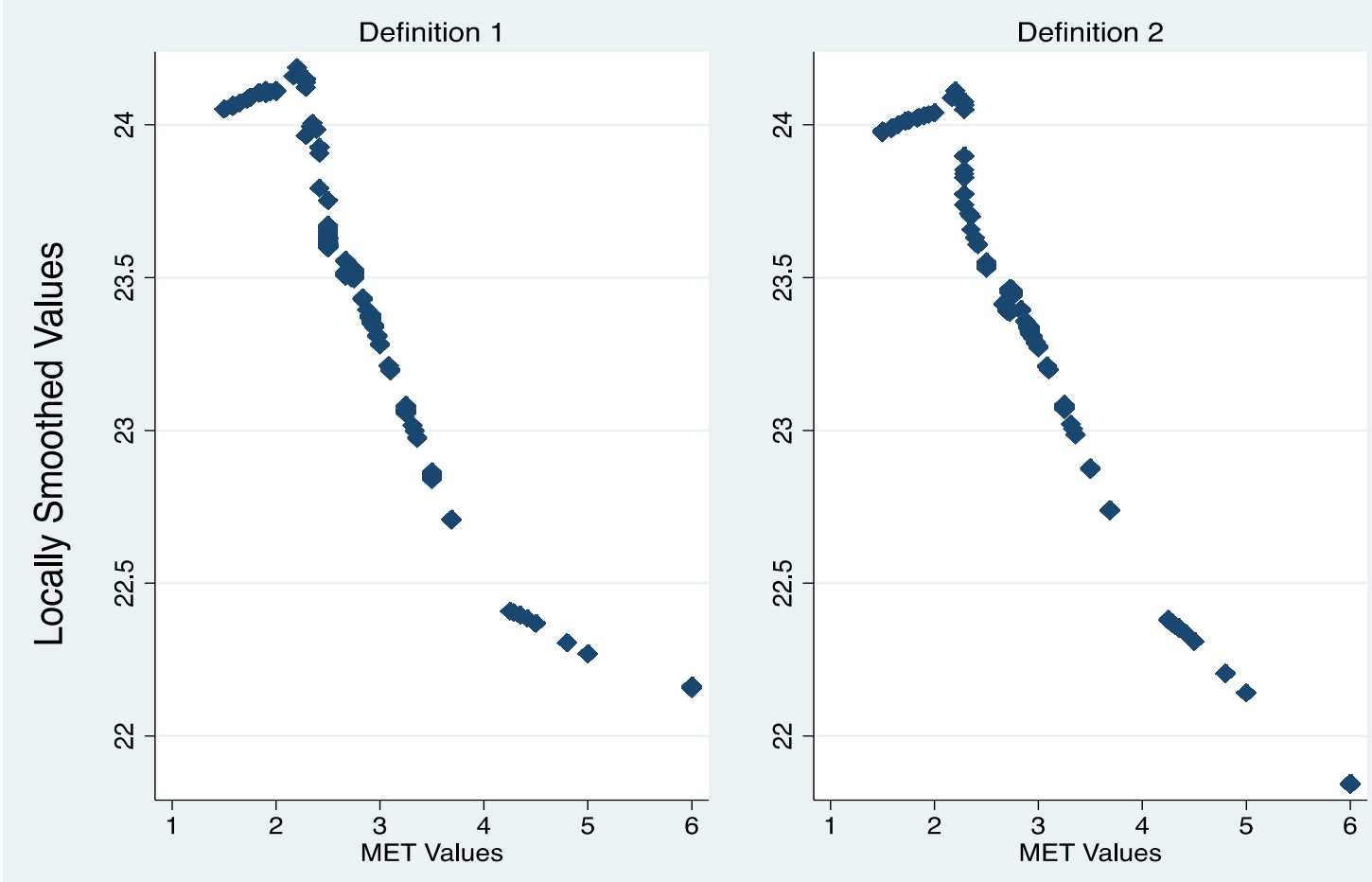

Panel B: Urban working men aged $18-60$
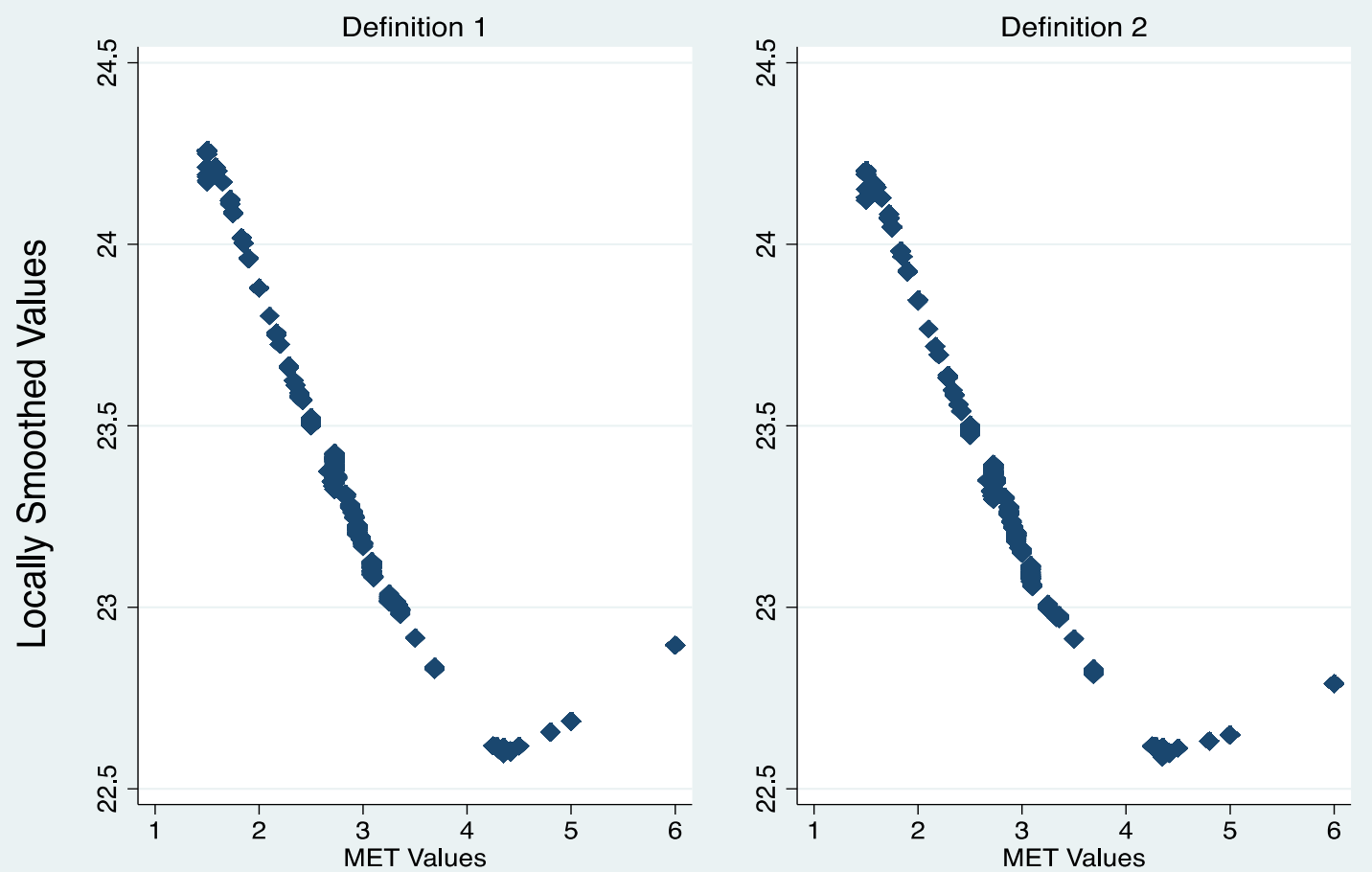

Notes: Lowess regression results. Sample in Panel A restricted to urban working women aged $18-60$ in IHDS1 and IHDS2. In Panel B, sample is restricted to urban working men aged $18-60$ in IHDS2. See Table A2 for the MET values associated with each occupation. 
Figure 4: Distribution of BMI by intensity of activity (defined by MET categories)

Panel A: Urban working women aged 18 - 60

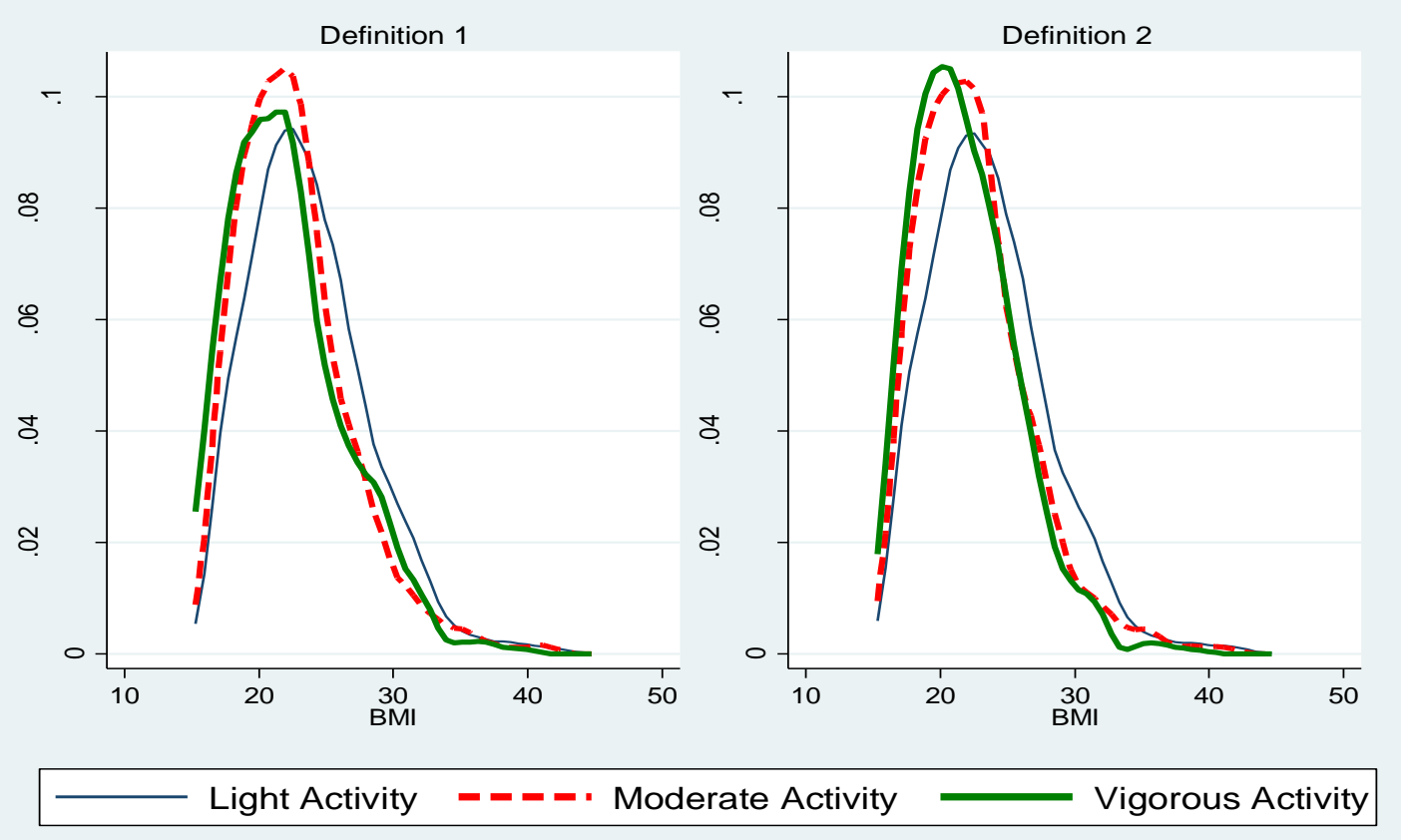

Panel B: Urban working men aged 18 - 60
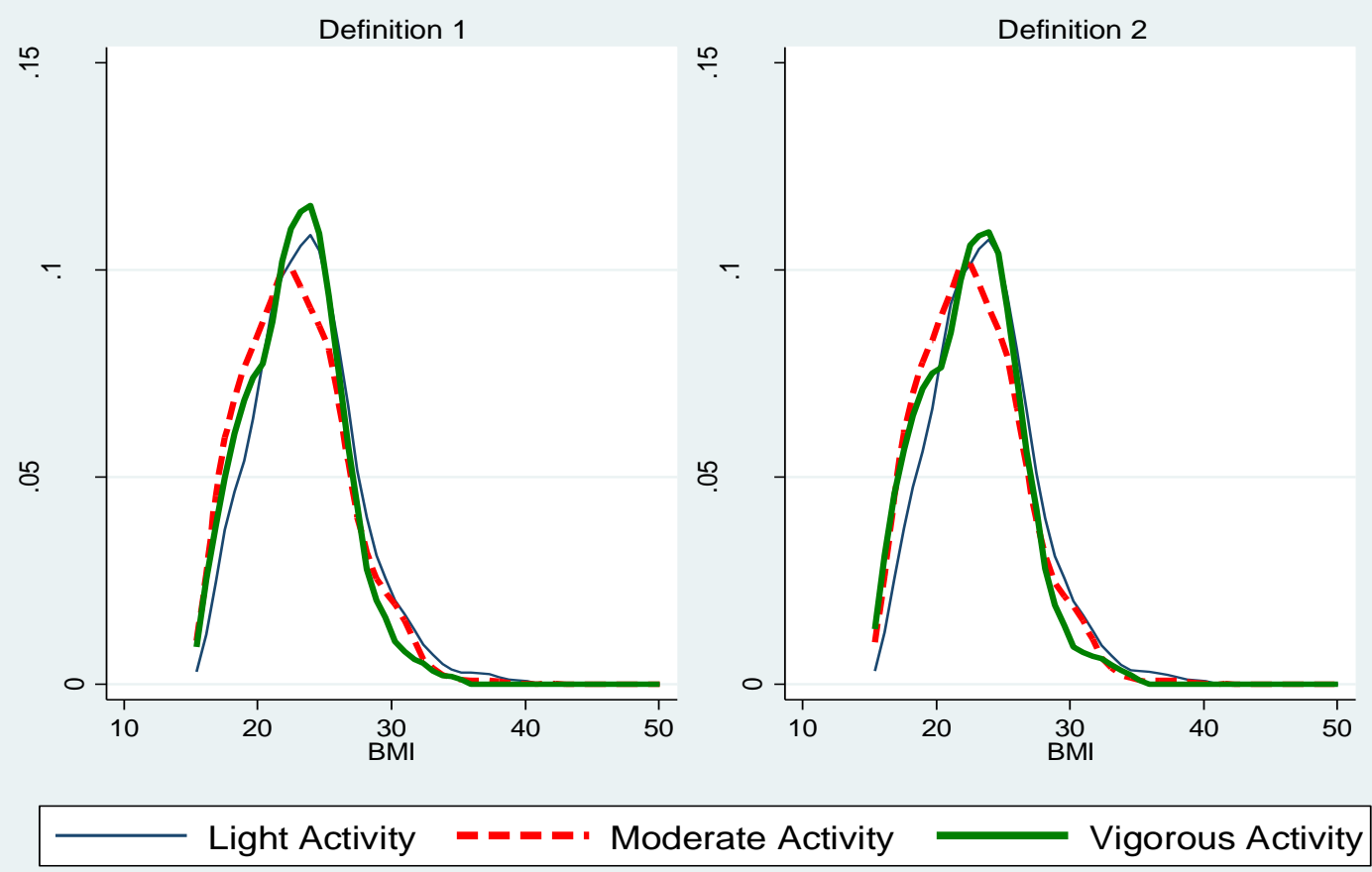

Notes: Kernel density estimates of BMI presented. Sample in Panel A restricted to urban working women aged 18 60 in IHDS1 and IHDS2. In Panel B, sample is restricted to urban working men aged 18-60 in IHDS2. See Table A2 for the MET values associated with each occupation. In Panel A, for Definition 1, K-S test p-values for equality of distributions are $0.00,0.00$ and 0.15 for the light and heavy, light and moderate, and moderate and vigorous intensity occupations, respectively. For Definition 2, the corresponding K-S test p-values are 0.00, 0.00 and 0.03. In Panel B, for Definition 1, K-S test p-values for equality of distributions are $0.00,0.00$ and 0.65 for the light and vigorous, light and moderate, and moderate and vigorous intensity occupations, respectively. For Definition 2, the corresponding K-S test p-values are $0.00,0.00$ and 0.57 . 
Figure 5: Distribution of BMI by work status Panel A: Urban working women aged 18 - 60
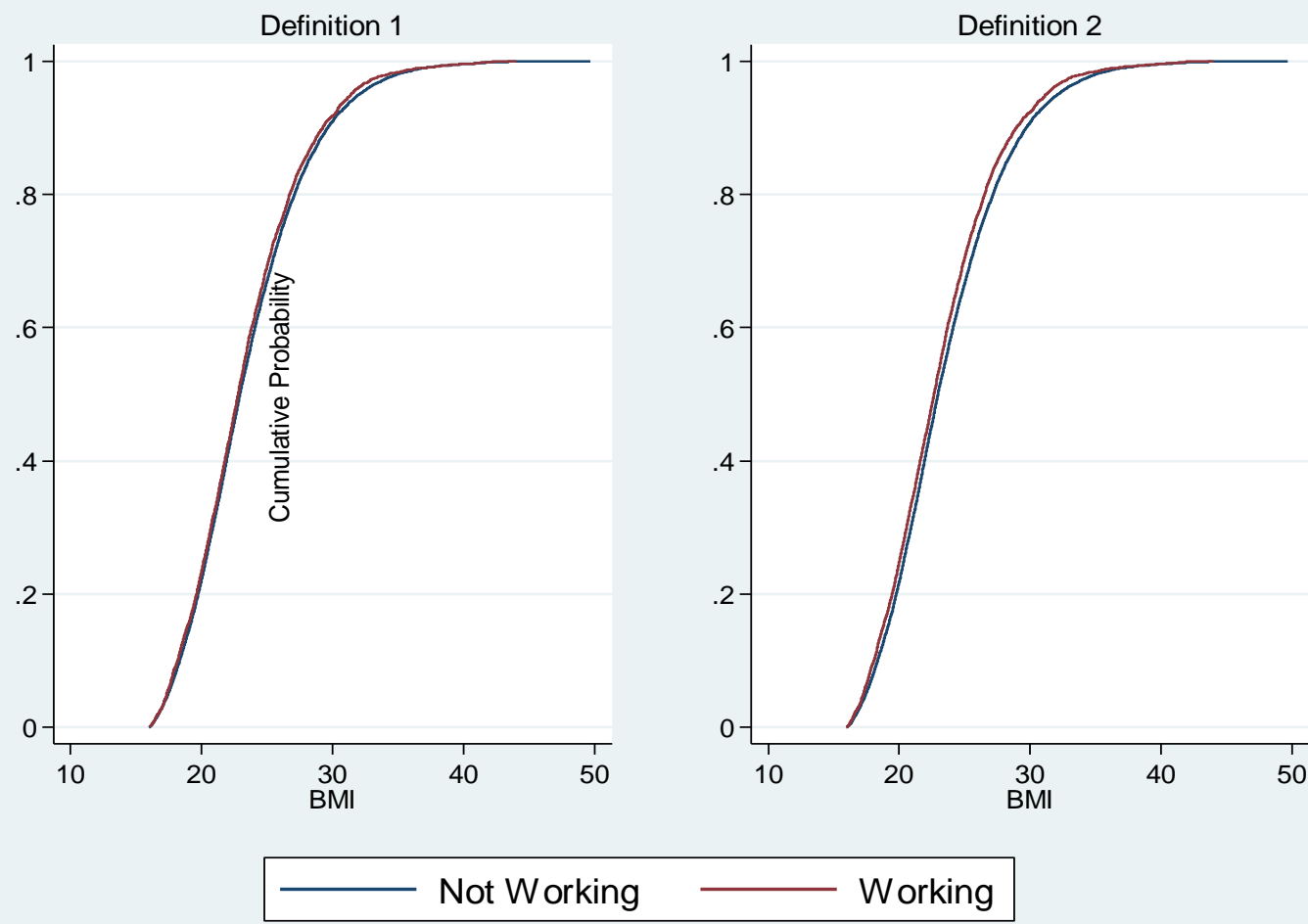

Panel B: Urban working men aged 18 - 60
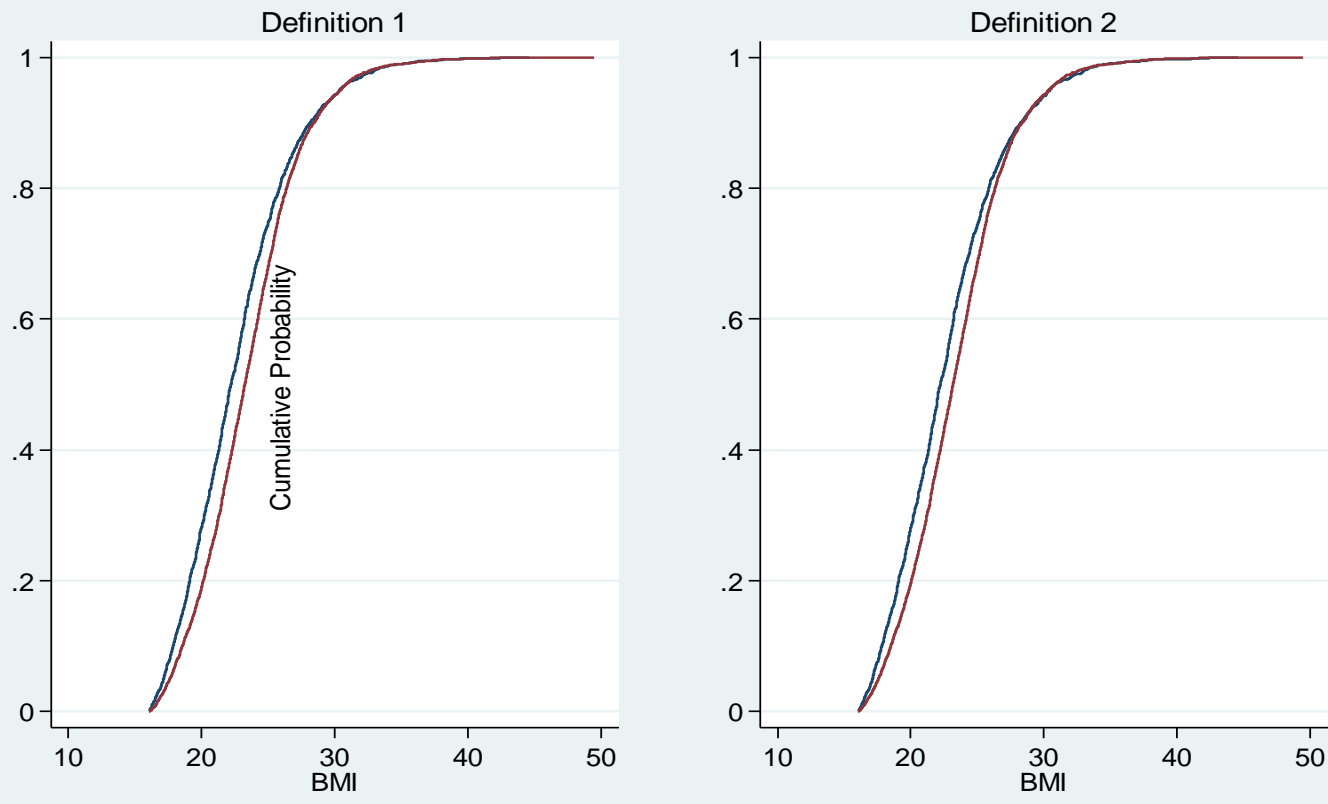

\section{Not Working}

Working

Notes: CDF of BMI presented. Sample in Panel A restricted to all urban women aged $18-60$ in IHDS1 and IHDS2. In Panel B, sample is restricted to all urban men aged $18-60$ in IHDS2. 
Table 1: Distribution of urban women and men by working status, occupational groups and physical strenuousness of work.

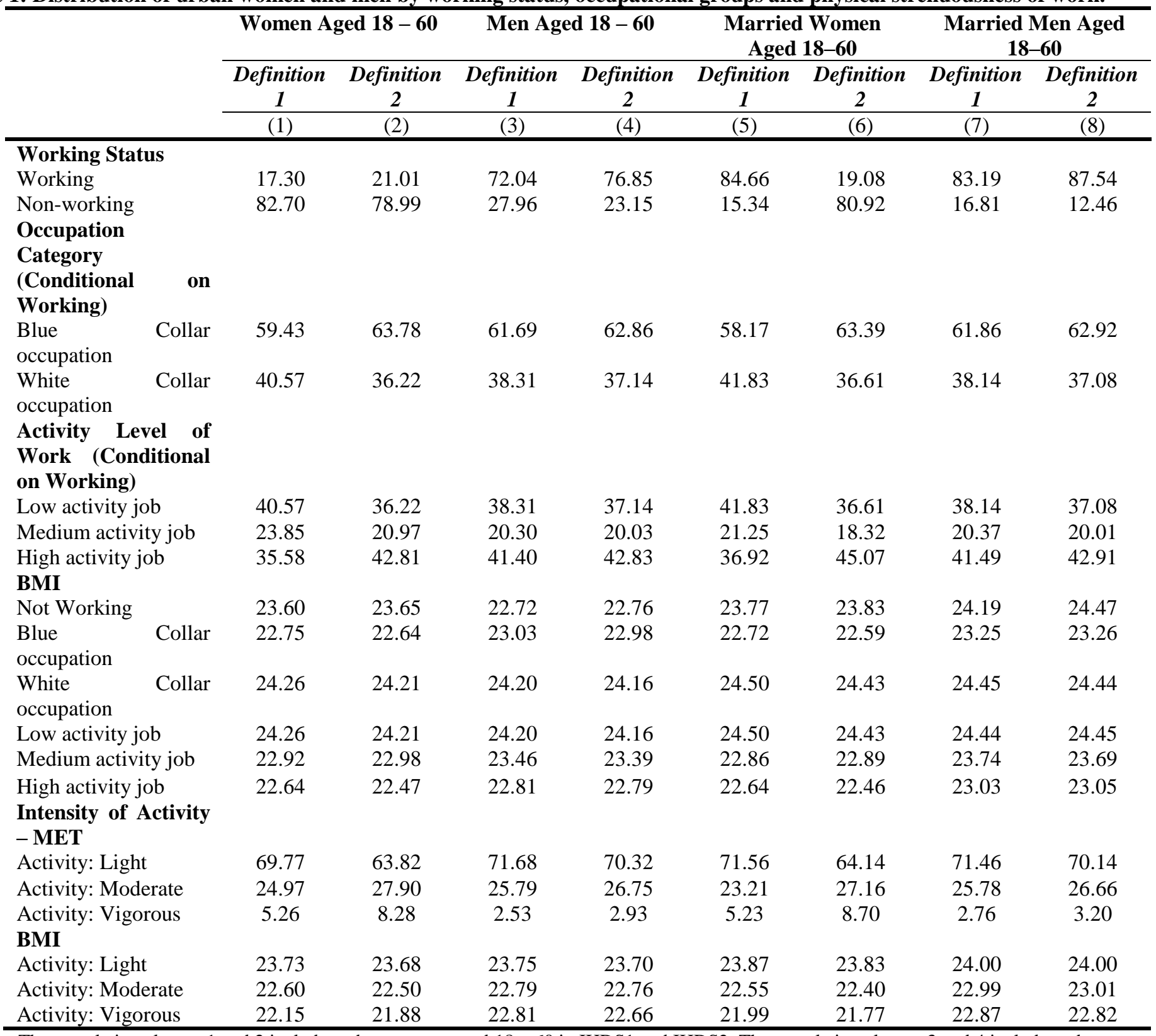

Notes: The sample in columns 1 and 2 includes urban women aged $18-60$ in IHDS1 and IHDS2. The sample in columns 3 and 4 includes urban men aged $18-60$ in IHDS2. In columns 5-8, the sample is restricted to those that are married. Table reports proportions except in the case of BMI where actual levels are reported. 
Table 2: OLS regression of BMI in IHDS1 on withdrawal from the labour market in IHDS2

\begin{tabular}{lcc}
\hline & Definition 1 & Definition 2 \\
\cline { 2 - 3 } & $(1)$ & $(2)$ \\
\hline BMI in 2004-05 & 0.003 & 0.001 \\
& $(0.005)$ & $(0.004)$ \\
Constant & $1.160^{* *}$ & $0.476^{*}$ \\
& $(0.420)$ & $(0.258)$ \\
\hline Sample size & 884 & 1,163 \\
\hline
\end{tabular}

Notes: Sample restricted to urban working women aged 18 and above at the time of survey in IHDS1, but aged less than 60 at the time of survey in IHDS2. The dependent variable takes value 1 if a woman stopped working in IHDS2, and takes value 0 if she continue to work in IHDS2. The regressions include IHDS1 individual (age, age square, years of education, marital status, whether or not the individual consumes tobacco, number of children, the average number of hours spent watching television) and household level (dummies for wealth quartiles, whether or not the household has domestic help, whether the household owns a car or a motor cycle, household religions, the share of total expenditure on eating outside) controls, and a set of state dummies. Standard errors clustered at the state level are in parenthesis. Significance: ${ }^{*} p<0.10,{ }^{* *} p<0.05,{ }^{* * *} p<0.01$. 
Table 3: Regression of BMI on labour market sector of work and intensity.

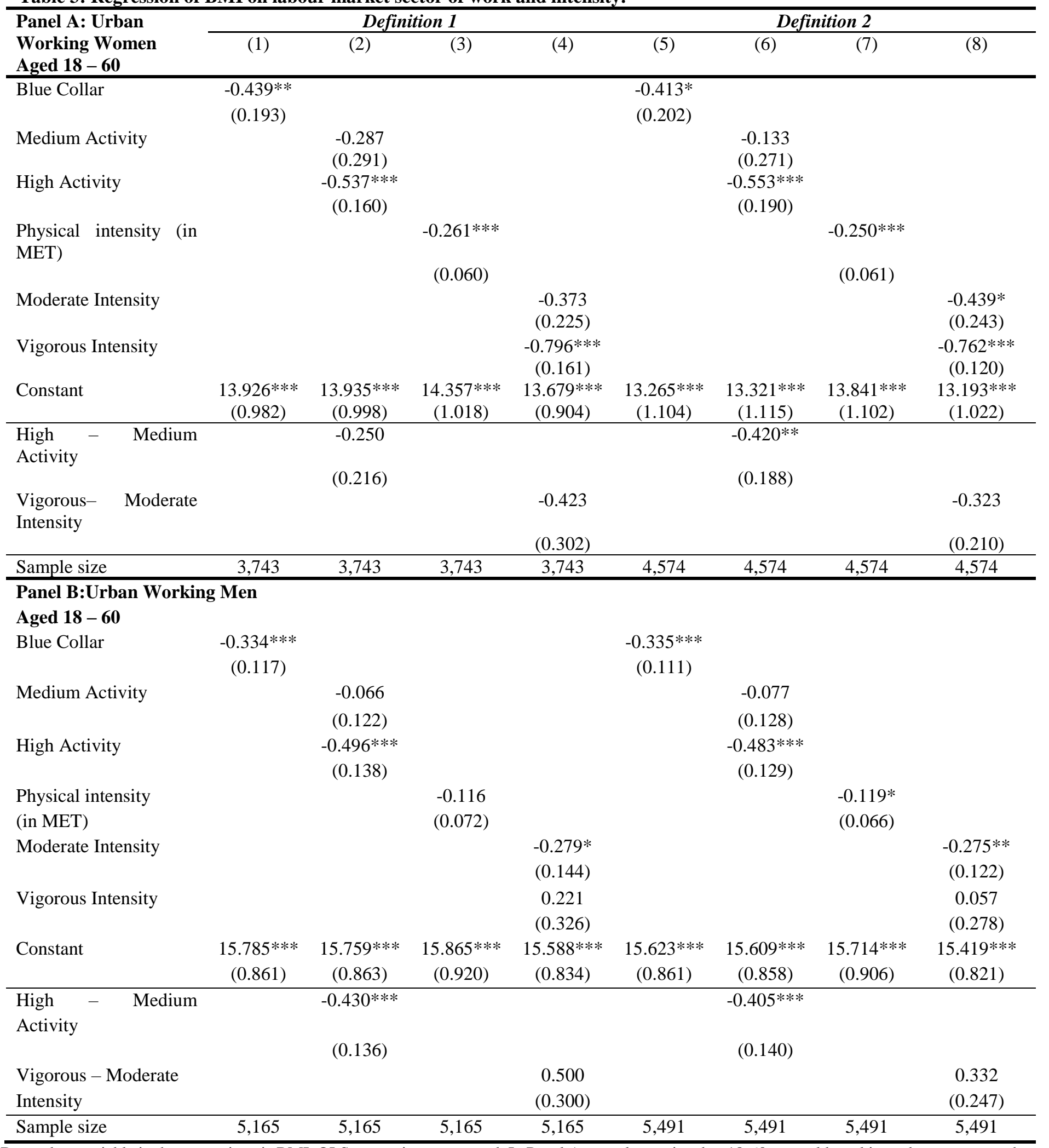

Notes: Dependent variable in the regressions is BMI. OLS regressions presented. In Panel A, sample restricted to 18-60-year-old working urban women at the time of survey in IHDS1 and IHDS2. In Panel B, sample restricted to 18-60-year-old working urban men in IHDS2. The regressions include individual (age, age square, years of education, marital status, whether or not the individual consumes tobacco, number of children, the average number of hours spent watching television) and household level (dummies for wealth quartiles, whether or not the household has domestic help, whether the household owns a car or a motor cycle, household religions, the share of total expenditure on eating outside) controls, and a set of state dummies. The regressions in Panel A also include an IHDS2 year dummy. Standard errors clustered at the state level are in parenthesis. Significance: ${ }^{*} p<0.10,{ }^{* *} p<0.05,{ }^{* * * *} p<0.01$ 
Table 4: Regression of BMI on labour market sector of work and intensity (full sample).

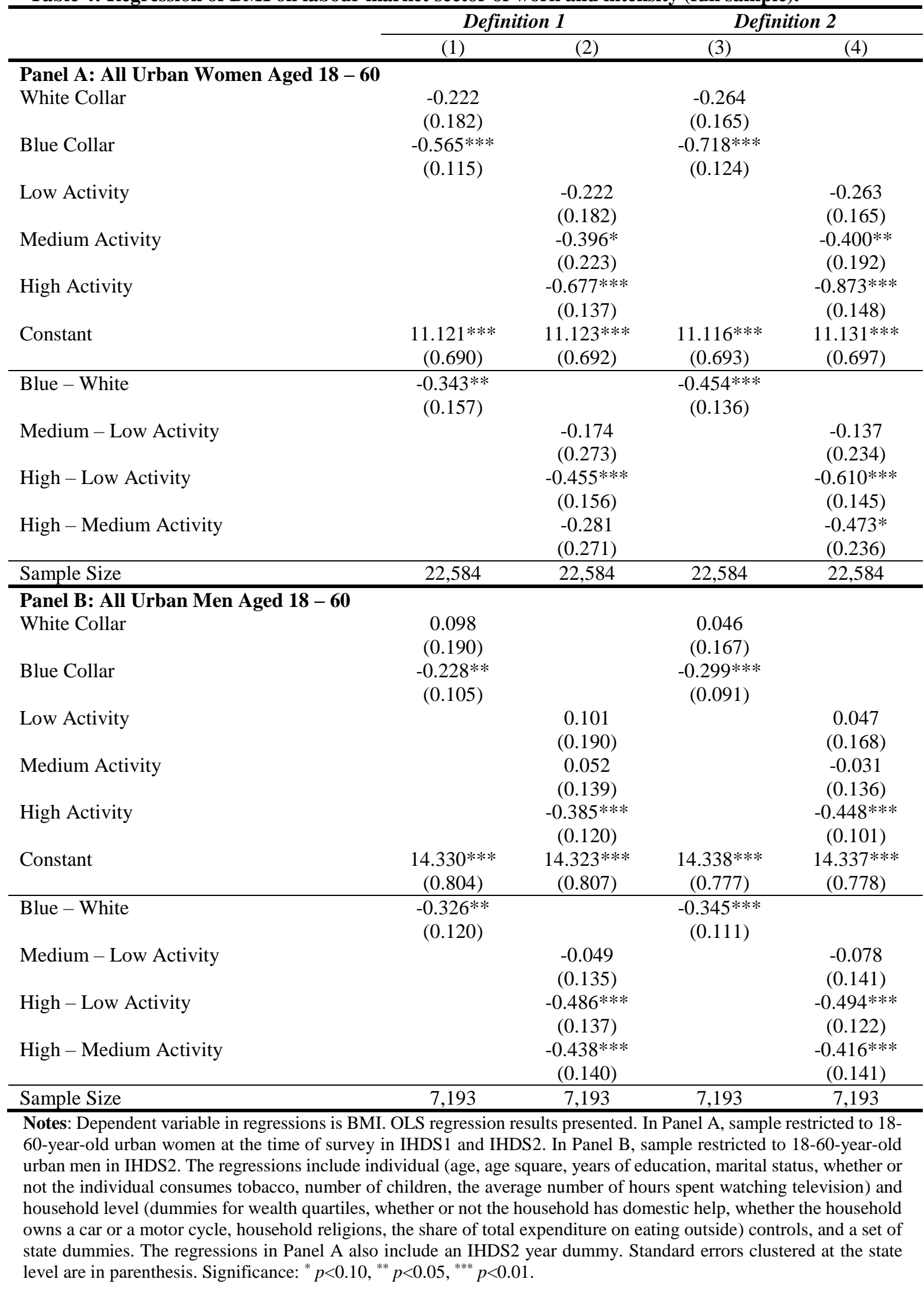


Table 5: BMI on labour market sector of work. Married sample

\begin{tabular}{|c|c|c|c|c|}
\hline & \multicolumn{2}{|c|}{ Definition 1} & \multicolumn{2}{|c|}{ Definition 2} \\
\hline & OLS & IV & OLS & IV \\
\hline & (1) & (2) & (3) & (4) \\
\hline \multicolumn{5}{|c|}{$\begin{array}{l}\text { Panel A: Urban Working Women } \\
\text { Aged 18-60 }\end{array}$} \\
\hline Blue collar & $\begin{array}{c}-0.553 * * \\
(0.212)\end{array}$ & $\begin{array}{c}-1.008 * * \\
(0.429)\end{array}$ & $\begin{array}{c}-0.499 * * \\
(0.206)\end{array}$ & $\begin{array}{l}-0.825^{*} \\
(0.443)\end{array}$ \\
\hline Constant & $\begin{array}{c}13.920 * * * \\
(1.531)\end{array}$ & & $\begin{array}{c}13.779 * * * \\
(1.603)\end{array}$ & \\
\hline First Stage F-statistic & & $\begin{array}{c}144.10 \\
{[0.000]}\end{array}$ & & $\begin{array}{l}195.57 \\
{[0.000]}\end{array}$ \\
\hline Hansen's $J \chi^{2}$ statistic & & $\begin{array}{c}0.399 \\
{[0.891]}\end{array}$ & & $\begin{array}{c}5.247 \\
{[0.073]}\end{array}$ \\
\hline Sample size & 2,353 & 2,353 & 3,076 & 3,076 \\
\hline $\begin{array}{l}\text { Panel B: Urban Work } \\
\text { Aged 18-60 }\end{array}$ & & & & \\
\hline Blue collar & $\begin{array}{c}-0.651 * * \\
(0.247)\end{array}$ & $\begin{array}{c}-1.178 * * * \\
(0.391)\end{array}$ & $\begin{array}{c}-0.623 * * * \\
(0.188)\end{array}$ & $\begin{array}{c}-1.307 * * * \\
(0.472)\end{array}$ \\
\hline Constant & $\begin{array}{c}18.322 * * * \\
(2.755)\end{array}$ & & $\begin{array}{c}17.656 * * * \\
(3.422)\end{array}$ & \\
\hline First Stage F-statistic & & $\begin{array}{c}59.10 \\
{[0.000]}\end{array}$ & & $\begin{array}{c}77.20 \\
{[0.000]}\end{array}$ \\
\hline Hansen's $J \chi^{2}$ statistic & & $\begin{array}{r}1.339 \\
{[0.512]}\end{array}$ & & $\begin{array}{c}1.199 \\
{[0.549]}\end{array}$ \\
\hline Sample size & 802 & 802 & 1,025 & 1,025 \\
\hline
\end{tabular}

Notes: Dependent variable is BMI. OLS and IV regression results presented. In Panel A, sample restricted to 18-60year-old working urban married women at the time of survey in IHDS1 and IHDS2. In Panel B, sample restricted to 18-60-year-old working urban married men in IHDS2. The regressions include individual (age, age square, years of education, marital status, whether or not the individual consumes tobacco, number of children, the average number of hours spent watching television) and household level (dummies for wealth quartiles, whether or not the household has domestic help, whether the household owns a car or a motor cycle, household religions, the share of total expenditure on eating outside) controls, and a set of state dummies. The regressions in Panel A also include an IHDS2 year dummy. English speaking ability and activity status of spouse (working spouses) are used as instruments. Standard errors clustered at the state level are in parenthesis. $p$-values are reported in square brackets. Significance: ${ }^{*} p<0.10,{ }^{* *} p<0.05$, ${ }^{* * * *} p<0.01$. 
Table 6: Regression of BMI on labour market intensity. Married sample

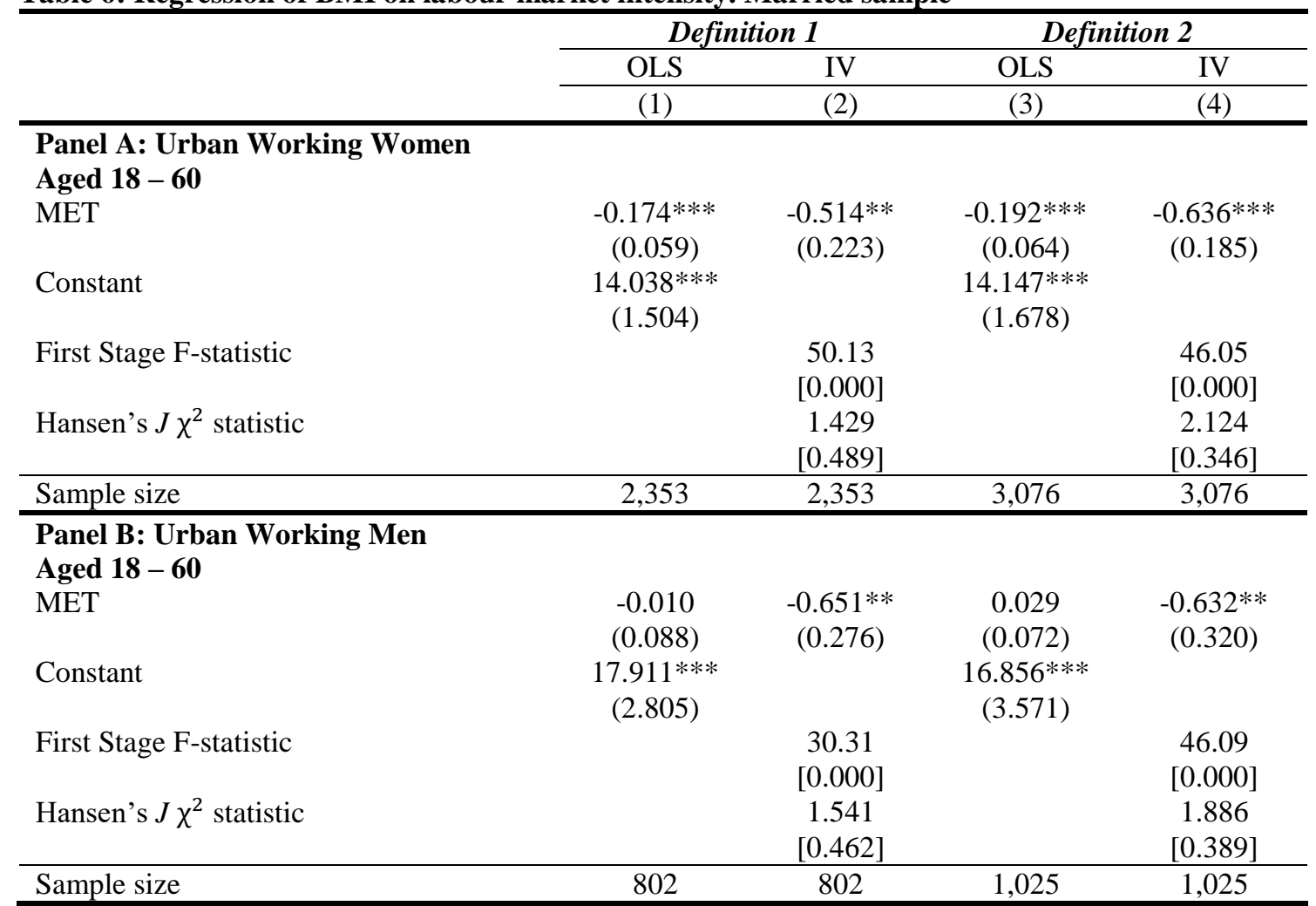

Notes: Dependent variable is BMI. OLS and IV regression results presented. In Panel A, sample restricted to 18-60year-old working urban married women at the time of survey in IHDS1 and IHDS2. In Panel B, sample restricted to 18-60-year-old working urban married men in IHDS2. The regressions include individual (age, age square, years of education, marital status, whether or not the individual consumes tobacco, number of children, the average number of hours spent watching television) and household level (dummies for wealth quartiles, whether or not the household has domestic help, whether the household owns a car or a motor cycle, household religions, the share of total expenditure on eating outside) controls, and a set of state dummies. The regressions in Panel A also include an IHDS2 year dummy. English speaking ability and activity status of spouse are used as instruments. Standard errors clustered at the state level are in parenthesis. $p$-values are reported in square brackets. Significance: ${ }^{*} p<0.10,{ }^{* *} p<0.05,{ }^{* * *} p<0.0$ 


\section{APPENDIX A}

Figure A1: Average MET values by sector of occupation and activity levels

Panel A: Average MET values by sector of occupation

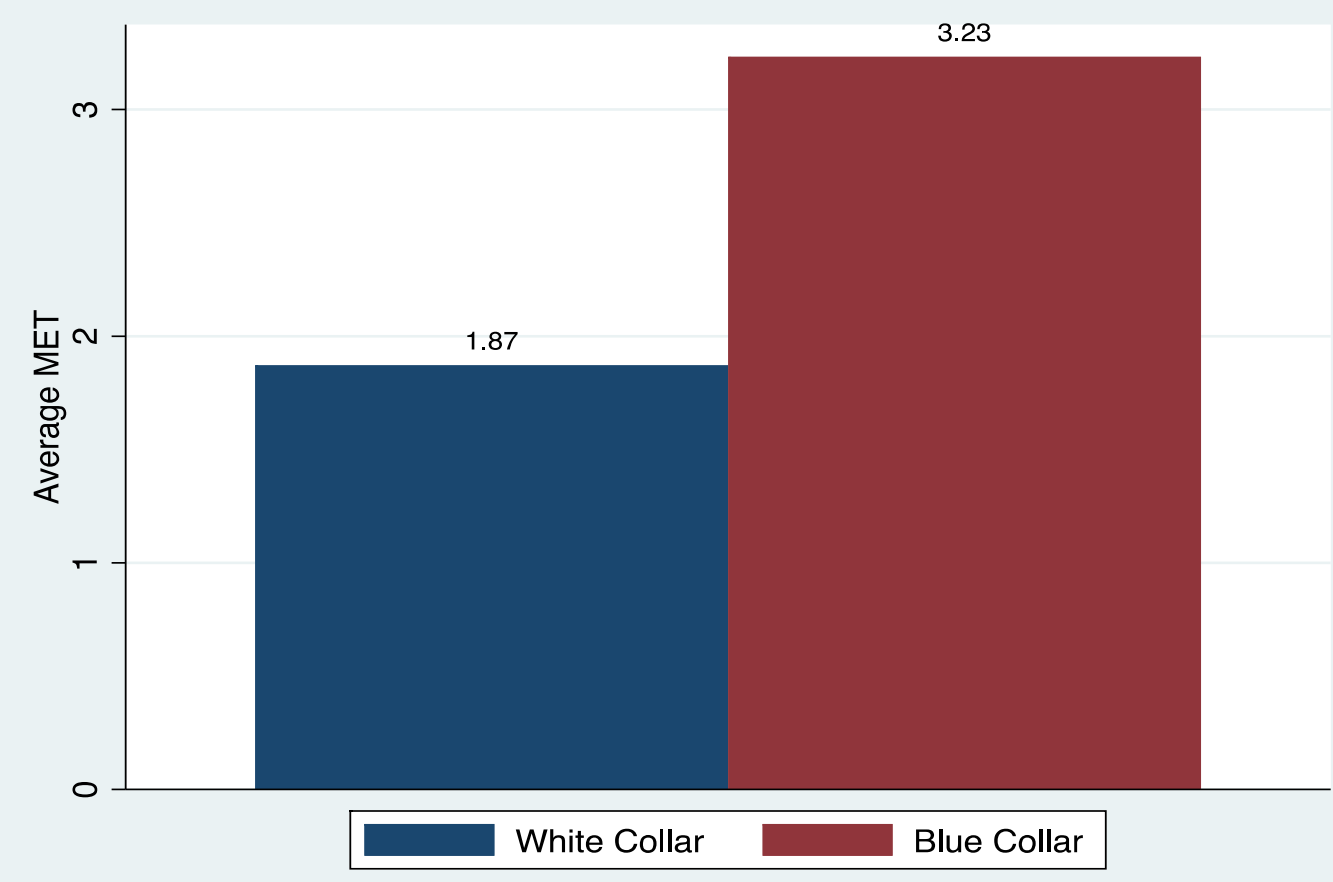

Panel B: Average MET values by activity levels

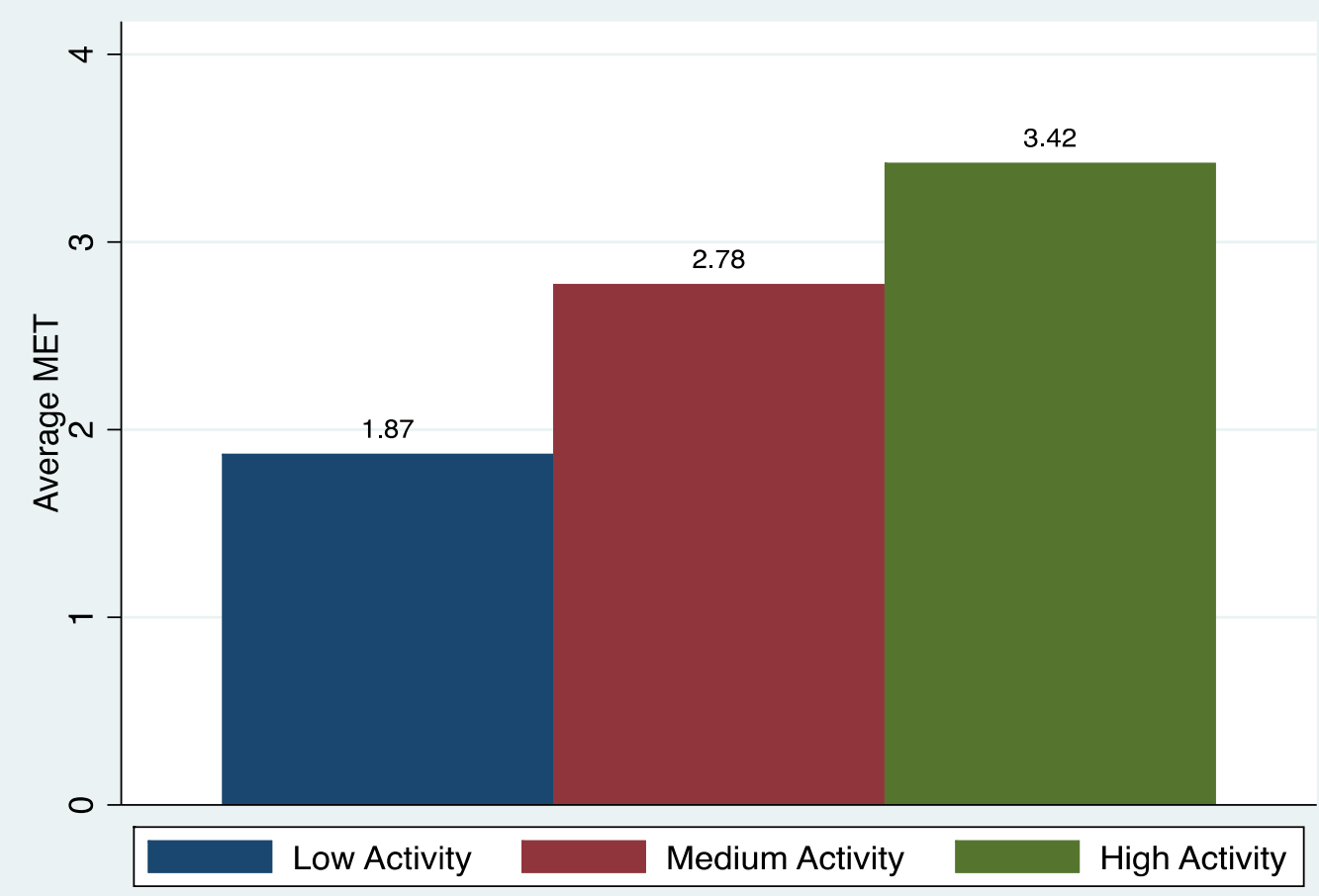

Notes: See Table A1 for the categorization of occupations and Table A2 for the corresponding MET values. 
Table A1: Categorization into type of occupation and physical activity level

\begin{tabular}{ll}
\hline Categorization & Occupational Groups \\
\hline Type of Occupation & $\begin{array}{l}\text { Professional, technical, and related workers, } \\
\text { administrative, executive, and managerial workers, } \\
\text { White collar jobs (non-manual jobs) }\end{array}$ \\
$\begin{array}{l}\text { Sales workers, Service workers, workers in transport } \\
\text { and communications, Farmers, fishermen, hunters, } \\
\text { Blue collar jobs (manual jobs) } \\
\text { loggers and related workers, Production and related } \\
\text { workers* }\end{array}$ \\
\hline
\end{tabular}

Physical activity level

Low (same as white collar jobs)

Medium

High
Professional, technical, and related workers, administrative, executive, and managerial workers, clerical and related workers ${ }^{* *}$

Sales workers, service workers and workers in transport and communications***

Farmers, fishermen, hunters, loggers and related workers, production, and related workers**

Notes: *Occupations coded $00-36,39,40,41,42,44$ and 45 as per NCO 1968 were categorized as white-collar jobs. Occupations coded as 37, 38, 49, 43 and 50-99, as per NCO 1968 were categorized as blue-collar jobs.

** Occupations coded $00-36,39,40,41,42,44,45$ as per NCO 1968 were categorized as low activity jobs. This is same as white collar jobs described above. Occupations coded as 37, 38, 43, 49, 86, 98 and 50 - 59 as per NCO 1968 were categorized medium activity jobs. Occupations coded $60-85,87-97$ and 99 as per NCO 1968 were categorized as high activity jobs 
Table A2: MET values of occupation.

\begin{tabular}{|c|c|c|c|c|c|}
\hline $\begin{array}{l}\text { Two- digit } \\
\text { occupation } \\
\text { code }\end{array}$ & Occupations & $\begin{array}{l}\text { Two- digit } \\
\text { MET value }\end{array}$ & $\begin{array}{l}\text { Intensity of } \\
\text { occupation }\end{array}$ & $\begin{array}{c}\text { Sector of } \\
\text { Occupation }\end{array}$ & Type of Activity \\
\hline 00 & Physical Scientists & 1.80 & Light & White Collar & Low Activity \\
\hline 01 & Physical Science Technicians & 2.50 & Light & White Collar & Low Activity \\
\hline 02 & $\begin{array}{l}\text { Architects, Engineers, } \\
\text { Technologists and Surveyors }\end{array}$ & 1.60 & Light & White Collar & Low Activity \\
\hline 03 & Engineering Technicians & 2.39 & Light & White Collar & Low Activity \\
\hline 04 & Aircraft and Ships Officers & 2.00 & Light & White Collar & Low Activity \\
\hline 05 & Life Scientists & 2.10 & Light & White Collar & Low Activity \\
\hline 06 & Life Science Technicians & 2.50 & Light & White Collar & Low Activity \\
\hline 07 & $\begin{array}{l}\text { Physicians and Surgeons } \\
\text { (Allopathic Dental and Veterinary } \\
\text { Surgeons) }\end{array}$ & 2.35 & Light & White Collar & Low Activity \\
\hline 08 & $\begin{array}{l}\text { Nursing and other Medical and } \\
\text { Health Technicians }\end{array}$ & 2.42 & Light & White Collar & Low Activity \\
\hline 09 & $\begin{array}{l}\text { Scientific, Medical and Technical } \\
\text { Persons, Other }\end{array}$ & 2.50 & Light & White Collar & Low Activity \\
\hline 10 & $\begin{array}{l}\text { Mathematicians, Statisticians and } \\
\text { Related Workers }\end{array}$ & 1.50 & Light & White Collar & Low Activity \\
\hline 11 & Economists and Related Workers & 1.50 & Light & White Collar & Low Activity \\
\hline 12 & $\begin{array}{l}\text { Accountants, Auditors and } \\
\text { Related Workers }\end{array}$ & 1.50 & Light & White Collar & Low Activity \\
\hline 13 & $\begin{array}{l}\text { Social Scientists and Related } \\
\text { Workers }\end{array}$ & 1.94 & Light & White Collar & Low Activity \\
\hline 14 & Jurists & 1.50 & Light & White Collar & Low Activity \\
\hline 15 & Teachers & 2.50 & Light & White Collar & Low Activity \\
\hline 16 & $\begin{array}{l}\text { Poets, Authors, Journalists and } \\
\text { Related Workers }\end{array}$ & 1.50 & Light & White Collar & Low Activity \\
\hline 17 & $\begin{array}{l}\text { Sculptors, Painters, Photographers } \\
\text { and Related Creative Artists }\end{array}$ & 3.00 & Light & White Collar & Low Activity \\
\hline 18 & Composers and Performing Artists & 2.33 & Light & White Collar & Low Activity \\
\hline 19 & Professional Workers, NEC & 2.20 & Light & White Collar & Low Activity \\
\hline 20 & Elected and Legislative Officials & 1.50 & Light & White Collar & Low Activity \\
\hline 21 & $\begin{array}{l}\text { Administrative and Executive } \\
\text { Officials Government and Local } \\
\text { Bodies }\end{array}$ & 2.00 & Light & White Collar & Low Activity \\
\hline 22 & $\begin{array}{l}\text { Working Proprietors, Directors } \\
\text { and Managers, Wholesale and } \\
\text { Retail Trade }\end{array}$ & 1.50 & Light & White Collar & Low Activity \\
\hline 23 & $\begin{array}{l}\text { Directors and Managers, Financial } \\
\text { Institutions }\end{array}$ & 1.50 & Light & White Collar & Low Activity \\
\hline 24 & $\begin{array}{l}\text { Working Proprietors, Directors } \\
\text { and Managers Mining, } \\
\text { Construction, Manufacturing and } \\
\text { Related Concerns }\end{array}$ & 1.90 & Light & White Collar & Low Activity \\
\hline 25 & $\begin{array}{l}\text { Working Proprietors, Directors, } \\
\text { Managers and Related Executives, } \\
\text { Transport, Storage and } \\
\text { Communication }\end{array}$ & 1.50 & Light & White Collar & Low Activity \\
\hline 26 & $\begin{array}{l}\text { Working Proprietors, Directors } \\
\text { and Managers, Other Service }\end{array}$ & 1.58 & Light & White Collar & Low Activity \\
\hline 29 & $\begin{array}{l}\text { Administrative, Executive and } \\
\text { Managerial Workers, NEC }\end{array}$ & 1.50 & Light & White Collar & Low Activity \\
\hline 30 & Clerical and Other Supervisors & 1.75 & Light & White Collar & Low Activity \\
\hline 31 & Village Officials & 1.50 & Light & White Collar & Low Activity \\
\hline 32 & $\begin{array}{l}\text { Stenographers, Typists and Card } \\
\text { and Tape Punching Operators }\end{array}$ & 1.65 & Light & White Collar & Low Activity \\
\hline
\end{tabular}




\section{Book-keepers \\ Related Workers}

\section{Computing Machine Operators}

Clerical and Related Workers, NEC

Transport and Communication Supervisors

\section{Transport Conductors and Guards}

Mail Distributors and Related

\section{Workers}

$$
\text { Telephone and Telegraph }
$$$$
\text { Operators }
$$

Merchants and Shopkeepers,

Wholesale and Retail Trade

\section{Manufacturers, Agents}

Technical Salesmen and

Commercial Travellers

Salesmen, Shop Assistants and Related Workers

Insurance, Real Estate, Securities and Business Service Salesmen and Auctioneers

Money Lenders and Pawn Brokers Sales Workers, NEC

Hotel and Restaurant Keepers

House Keepers, Matron and Stewards (Domestic and Institutional)

Cooks, Waiters, Bartenders and

Related Worker (Domestic and Institutional)

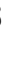

Maids and Other House Keeping Service Workers NEC

\section{Building Caretakers, Sweepers,} Cleaners and Related Workers

5

$$
\text { Launderers, Dry-cleaners and }
$$$$
\text { Pressers }
$$

Hair Dressers, Barbers, Beauticians and Related Workers

\section{Protective Service Workers}

Service Workers, NEC

Farm Plantation, Dairy and Other Managers and Supervisors

\section{Cultivators}

Farmers other than cultivators

Agricultural Labourers

Plantation Labourers and Related

Workers

Other Farm Workers

Forestry Workers

Hunters and Related Workers

Fishermen and Related Workers

Miners, Quarrymen, Well Drillers

\section{and Related Workers}

Metal Processors

Wood Preparation Workers and

Paper Makers

Chemical Processors and Related Workers

$\begin{array}{llll}1.50 & \begin{array}{l}\text { Light } \\ \text { Light }\end{array} & \begin{array}{l}\text { White Collar } \\ \text { White Collar }\end{array} & \begin{array}{l}\text { Low Activity } \\ \text { Low Activity }\end{array} \\ 2.17 & \text { Light } & \text { White Collar } & \text { Low Activity } \\ 2.00 & \begin{array}{c}\text { Light } \\ \text { Moderate }\end{array} & \begin{array}{l}\text { Blue Collar } \\ \text { Blue Collar }\end{array} & \begin{array}{l}\text { Medium Activity } \\ \text { Medium Activity }\end{array} \\ 1.50 & \text { Light } & \text { White Collar } & \text { Low Activity } \\ 1.50 & \text { Light } & \text { White Collar } & \text { Low Activity } \\ 1.75 & \text { Light } & \text { White Collar } & \text { Low Activity } \\ 2.00 & \text { Light } & \text { White Collar } & \text { Low Activity } \\ 2.50 & \text { Light } & \text { Blue Collar } & \text { Medium Activity } \\ 1.83 & \text { Light } & \text { White Collar } & \text { Low Activity }\end{array}$

$$
\text { Light }
$$

Moderate

Light

\section{Light}

Moderate

Moderate

Moderate

Vigorous

Vigorous

Moderate

Moderate

Moderate

Moderate

Moderate

2.71
Light

Light

Blue Collar Blue Collar
White Collar Blue Collar Blue Collar Blue Collar

Blue Collar

Medium Activity

Blue Collar

Medium Activity

Blue Collar

Blue Collar

Blue Collar

Light

Light

Blue Collar

Blue Collar

Blue Collar

Blue Collar

Blue Collar

Blue Collar

Blue Collar

Blue Collar

Blue Collar

Blue Collar

Blue Collar

Blue Collar

Low Activity

Medium Activity

Medium Activity

Medium Activity

Medium Activity

Medium Activity

Medium Activity

Medium Activity

Medium Activity

High Activity

High Activity

High Activity

High Activity

High Activity

High Activity

High Activity

High Activity

High Activity

High Activity

High Activity

High Activity

Light Blue Collar High Activity 


\begin{tabular}{|c|c|c|c|c|c|}
\hline 75 & $\begin{array}{l}\text { Spinners, Weavers, Knitters, } \\
\text { Dyers and Related Workers }\end{array}$ & 2.73 & Light & Blue Collar & High Activity \\
\hline 76 & $\begin{array}{l}\text { Tanners, Fellmongers and Pelt } \\
\text { Dressers }\end{array}$ & 3.25 & & Blue Collar & High Activity \\
\hline 77 & Food and Beverage Processors & 2.70 & Light & Blue Collar & High Activity \\
\hline 78 & $\begin{array}{l}\text { Tobacco Preparers and Tobacco } \\
\text { Product Makers }\end{array}$ & 2.92 & Light & Blue Collar & High Activity \\
\hline 79 & $\begin{array}{l}\text { Tailors, Dress Makers, Sewers, } \\
\text { Upholsterers and Related Workers }\end{array}$ & 2.29 & Light & Blue Collar & High Activity \\
\hline 80 & $\begin{array}{l}\text { Shoe makers and Leather Goods } \\
\text { Makers }\end{array}$ & 2.50 & Light & Blue Collar & High Activity \\
\hline 81 & $\begin{array}{l}\text { Carpenters, Cabinet and Related } \\
\text { Wood Workers }\end{array}$ & 3.43 & Moderate & Blue Collar & High Activity \\
\hline 82 & Stone Cutters and Carvers & 2.83 & Light & Blue Collar & High Activity \\
\hline 83 & $\begin{array}{l}\text { Blacksmiths, Tool Makers and } \\
\text { Machine Tool Operators }\end{array}$ & 3.31 & Moderate & Blue Collar & High Activity \\
\hline 84 & $\begin{array}{lcc}\text { Machinery } & \text { Fitters, } & \text { Machine } \\
\text { Assemblers } & \text { and } & \text { Precision } \\
\text { Instrument } & & \end{array}$ & 3.08 & Moderate & Blue Collar & High Activity \\
\hline 85 & $\begin{array}{l}\text { Electrical Fitters and Related } \\
\text { Electrical and Electronic Workers }\end{array}$ & 2.94 & Light & Blue Collar & High Activity \\
\hline 86 & $\begin{array}{l}\text { Broadcasting Station and Sound } \\
\text { Equipment Operators and Cinema } \\
\text { Projectionists }\end{array}$ & 2.00 & Light & Blue Collar & Medium Activity \\
\hline 87 & $\begin{array}{l}\text { Plumbers, Welders, Sheet Metal } \\
\text { and Structural Metal Preparers and } \\
\text { Erectors }\end{array}$ & 4.42 & Moderate & Blue Collar & High Activity \\
\hline 88 & $\begin{array}{l}\text { Jewellery and Precious Metal } \\
\text { Workers and Metal Engravers } \\
\text { (Except Printing) }\end{array}$ & 1.50 & Light & Blue Collar & High Activity \\
\hline 89 & $\begin{array}{l}\text { Glass Formers, Potters and } \\
\text { Related Workers }\end{array}$ & 2.50 & Light & Blue Collar & High Activity \\
\hline 90 & $\begin{array}{l}\text { Rubber and Plastic Product } \\
\text { Makers }\end{array}$ & 3.10 & Moderate & Blue Collar & High Activity \\
\hline 91 & $\begin{array}{l}\text { Paper and Paper Board Products } \\
\text { Makers }\end{array}$ & 2.83 & Light & Blue Collar & High Activity \\
\hline 92 & Printing and Related Workers & 1.85 & Light & Blue Collar & High Activity \\
\hline 93 & Painters & 2.88 & Light & Blue Collar & High Activity \\
\hline 94 & $\begin{array}{l}\text { Production and Related Workers, } \\
\text { NEC }\end{array}$ & 2.90 & Light & Blue Collar & High Activity \\
\hline 95 & $\begin{array}{l}\text { Bricklayers } \quad \text { and } \\
\text { Constructions Workers }\end{array}$ & 4.35 & Moderate & Blue Collar & High Activity \\
\hline 96 & $\begin{array}{l}\text { Stationery Engines and Related } \\
\text { Equipment Operators, Oilers and } \\
\text { Greasors }\end{array}$ & 3.10 & Moderate & Blue Collar & High Activity \\
\hline 97 & $\begin{array}{l}\text { Material Handling and Related } \\
\text { Equipment Operators, Loaders } \\
\text { and Unloaders }\end{array}$ & 3.69 & Moderate & Blue Collar & High Activity \\
\hline 98 & Transport Equipment Operators & 2.73 & Light & Blue Collar & Medium Activity \\
\hline 99 & Labourers NEC & 5.00 & Moderate & Blue Collar & High Activity \\
\hline
\end{tabular}


Table A3: First stage IV regression results.

\begin{tabular}{|c|c|c|c|c|}
\hline & \multicolumn{2}{|c|}{ Blue collar job } & \multicolumn{2}{|c|}{ MET } \\
\hline & Definition 1 & Definition 2 & Definition 1 & Definition 2 \\
\hline & $(1)$ & $(2)$ & $(3)$ & $(4)$ \\
\hline \multicolumn{5}{|l|}{$\begin{array}{l}\text { Panel A: Urban Married Working } \\
\text { Women Aged } 18-60\end{array}$} \\
\hline Spoken English (Moderate or Fluent) & $\begin{array}{c}-0.114 * * * \\
(0.036)\end{array}$ & $\begin{array}{l}-0.142 * * * \\
(0.030)\end{array}$ & $\begin{array}{l}0.114 * \\
(0.065)\end{array}$ & $\begin{array}{c}0.047 \\
(0.085)\end{array}$ \\
\hline Spouse employed in Medium Activity & $\begin{array}{l}0.319 * * * \\
(0.022)\end{array}$ & $\begin{array}{l}0.318 * * * \\
(0.022)\end{array}$ & $\begin{array}{c}0.325 * * * \\
(0.044)\end{array}$ & $\begin{array}{c}0.342 * * * \\
(0.051)\end{array}$ \\
\hline Spouse employed in High Activity & $\begin{array}{c}0.373 * * * \\
(0.021)\end{array}$ & $\begin{array}{c}0.371 * * * \\
(0.023)\end{array}$ & $\begin{array}{c}0.750 * * * \\
(0.065)\end{array}$ & $\begin{array}{c}0.836 * * * \\
(0.072)\end{array}$ \\
\hline First Stage F-statistic & $\begin{array}{c}144.10 \\
{[0.000]}\end{array}$ & $\begin{array}{l}195.57 \\
{[0.000]}\end{array}$ & $\begin{array}{c}50.13 \\
{[0.000]}\end{array}$ & $\begin{array}{c}46.05 \\
{[0.000]}\end{array}$ \\
\hline Hansen's $J \chi^{2}$ statistic & $\begin{array}{c}0.399 \\
{[0.891]}\end{array}$ & $\begin{array}{c}5.247 \\
{[0.073]}\end{array}$ & $\begin{array}{c}1.429 \\
{[0.489]}\end{array}$ & $\begin{array}{c}2.124 \\
{[0.346]}\end{array}$ \\
\hline Sample size & 2,353 & 3,076 & 2,353 & 3,076 \\
\hline \multicolumn{5}{|l|}{$\begin{array}{l}\text { Panel B: Urban Married Working Men } \\
\text { Aged 18-60 }\end{array}$} \\
\hline Spoken English (Moderate or Fluent) & $\begin{array}{c}-0.059 * * \\
(0.029)\end{array}$ & $\begin{array}{c}-0.068 * * \\
(0.029)\end{array}$ & $\begin{array}{l}-0.048 \\
(0.074)\end{array}$ & $\begin{array}{l}-0.084 \\
(0.071)\end{array}$ \\
\hline Spouse employed in Medium Activity & $\begin{array}{c}0.421 * * * \\
(0.038)\end{array}$ & $\begin{array}{c}0.417 * * * \\
(0.031)\end{array}$ & $\begin{array}{l}0.563 * * * \\
(0.109)\end{array}$ & $\begin{array}{c}0.460 * * * \\
(0.106)\end{array}$ \\
\hline Spouse employed in High Activity & $\begin{array}{c}0.465 * * * \\
(0.035)\end{array}$ & $\begin{array}{c}0.436 * * * \\
(0.028)\end{array}$ & $\begin{array}{l}0.913 * * * \\
(0.096)\end{array}$ & $\begin{array}{c}0.849 * * * \\
(0.083)\end{array}$ \\
\hline First Stage F-statistic & $\begin{array}{c}59.10 \\
{[0.000]}\end{array}$ & $\begin{array}{c}77.20 \\
{[0.000]}\end{array}$ & $\begin{array}{c}30.31 \\
{[0.000]}\end{array}$ & $\begin{array}{c}46.09 \\
{[0.000]}\end{array}$ \\
\hline \multirow[t]{2}{*}{ Hansen's $J \chi^{2}$ statistic } & 1.339 & 1.199 & 1.541 & 1.886 \\
\hline & [0.512] & [0.549] & {$[0.462]$} & [0.389] \\
\hline Sample size & 802 & 1,025 & 802 & 1,025 \\
\hline
\end{tabular}

Notes: Dependent variables are blue collar job (column 1 and 2) and MET (column 3 and 4) respectively. In Panel A, Sample restricted to 18-60-year-old married working urban women at the time of survey. In Panel B, sample restricted to 18-60-year-old married working urban men. The regressions include individual (age, age square, years of education, marital status, whether or not the individual consumes tobacco, number of children, the average number of hours spent watching television) and household level (dummies for wealth quartiles, whether or not the household has domestic help, whether the household owns a car or a motor cycle, household religions, the share of total expenditure on eating outside) controls, and a set state dummies. The regressions in Panel A also include an IHDS2 year dummy. English speaking ability and activity status of spouse are used as instruments. Standard errors clustered at the state level are in parenthesis. $p$-values are reported in square brackets. Significance: ${ }^{*} p<0.10,{ }^{* * *} p<0.05,{ }^{* * * *} p<0.00$. 
Table A4: Instrument Validity. Regressions of instrument on BMI. Married Women Sample.

\begin{tabular}{|c|c|c|c|c|c|c|c|c|}
\hline & \multicolumn{4}{|c|}{ Definition 1} & \multicolumn{4}{|c|}{ Definition 2} \\
\hline & $(1)$ & (2) & (3) & (4) & $(5)$ & (6) & (7) & $(8)$ \\
\hline \multirow{2}{*}{$\begin{array}{l}\text { Spoken English } \\
\text { (Moderate or Fluent) }\end{array}$} & 0.59 & & 0.148 & & -0.113 & & -0.027 & \\
\hline & $(0.218)$ & & $(0.218)$ & & $(0.270)$ & & $(0.269)$ & \\
\hline \multirow{2}{*}{$\begin{array}{l}\text { Spouse employed in } \\
\text { Medium Activity }\end{array}$} & & -0.082 & & -0.190 & & 0.234 & & 0.149 \\
\hline & & $(0.327)$ & & $(0.279)$ & & $(0.251)$ & & $(0.219)$ \\
\hline \multirow{2}{*}{$\begin{array}{l}\text { Spouse employed in } \\
\text { High Activity }\end{array}$} & & -0.233 & & -0.304 & & -0.302 & & $-0.332 *$ \\
\hline & & $(0.231)$ & & $(0.192)$ & & $(0.205)$ & & $(0.169)$ \\
\hline Blue collar & $\begin{array}{c}-0.548 * * \\
(0.209)\end{array}$ & $\begin{array}{l}-0.471 * \\
(0.271)\end{array}$ & & & $\begin{array}{c}-0.512 * * \\
(0.196)\end{array}$ & $\begin{array}{l}-0.423^{*} \\
(0.234)\end{array}$ & & \\
\hline MET & & & $\begin{array}{c}-0.175 * * * \\
(0.060)\end{array}$ & $\begin{array}{c}-0.143 * * \\
(0.060)\end{array}$ & & & $\begin{array}{c}-0.192 * * * \\
(0.064)\end{array}$ & $\begin{array}{c}-0.154 * * \\
(0.058)\end{array}$ \\
\hline Age & $\begin{array}{l}0.383 * * * \\
(0.065)\end{array}$ & $\begin{array}{c}0.382 * * * \\
(0.066)\end{array}$ & $\begin{array}{c}0.384 * * * \\
(0.066)\end{array}$ & $\begin{array}{c}0.384 * * * \\
(0.066)\end{array}$ & $\begin{array}{c}0.372 * * * \\
(0.072)\end{array}$ & $\begin{array}{c}0.368 * * * \\
(0.071)\end{array}$ & $\begin{array}{c}0.371 * * * \\
(0.072)\end{array}$ & $\begin{array}{c}0.368 * * * \\
(0.071)\end{array}$ \\
\hline Age square & $\begin{array}{c}-0.004 * * * \\
(0.001)\end{array}$ & $\begin{array}{c}-0.004 * * * \\
(0.001)\end{array}$ & $\begin{array}{c}-0.004 * * * \\
(0.001)\end{array}$ & $\begin{array}{c}-0.004 * * * \\
(0.001)\end{array}$ & $\begin{array}{c}-0.004 * * * \\
(0.001)\end{array}$ & $\begin{array}{c}-0.004 * * * \\
(0.001)\end{array}$ & $\begin{array}{c}-0.004 * * * \\
(0.001)\end{array}$ & $\begin{array}{c}-0.004 * * * \\
(0.001)\end{array}$ \\
\hline Years of education & $\begin{array}{c}0.031 * * \\
(0.013)\end{array}$ & $\begin{array}{c}0.032 * * \\
(0.014)\end{array}$ & $\begin{array}{c}0.036^{* * * *} \\
(0.010)\end{array}$ & $\begin{array}{c}0.039 * * * \\
(0.014)\end{array}$ & $\begin{array}{c}0.040 * * \\
(0.016)\end{array}$ & $\begin{array}{c}0.032 * * \\
(0.012)\end{array}$ & $\begin{array}{c}0.040 * * * \\
(0.014)\end{array}$ & $\begin{array}{c}0.035^{* * * *} \\
(0.011)\end{array}$ \\
\hline Smokes tobacco & $\begin{array}{l}-0.213 \\
(0.630)\end{array}$ & $\begin{array}{l}-0.198 \\
(0.652)\end{array}$ & $\begin{array}{l}-0.258 \\
(0.623)\end{array}$ & $\begin{array}{l}-0.232 \\
(0.648)\end{array}$ & $\begin{array}{l}-0.509 \\
(0.393)\end{array}$ & $\begin{array}{l}-0.474 \\
(0.404)\end{array}$ & $\begin{array}{l}-0.525 \\
(0.395)\end{array}$ & $\begin{array}{l}-0.487 \\
(0.405)\end{array}$ \\
\hline \multirow{2}{*}{$\begin{array}{l}\text { Hours watching } \\
\text { Television }\end{array}$} & 0.099 & 0.098 & 0.089 & 0.091 & $0.087 * *$ & $0.085 * *$ & $0.082 *$ & $0.081 *$ \\
\hline & $(0.063)$ & $(0.064)$ & $(0.065)$ & $(0.065)$ & $(0.039)$ & $(0.039)$ & $(0.041)$ & $(0.041)$ \\
\hline Number of children & $\begin{array}{l}-0.085 \\
(0.085)\end{array}$ & $\begin{array}{l}-0.085 \\
(0.085)\end{array}$ & $\begin{array}{l}-0.082 \\
(0.085)\end{array}$ & $\begin{array}{l}-0.082 \\
(0.085)\end{array}$ & $\begin{array}{l}-0.155^{*} \\
(0.079)\end{array}$ & $\begin{array}{l}-0.158^{*} \\
(0.079)\end{array}$ & $\begin{array}{l}-0.154 * \\
(0.078)\end{array}$ & $\begin{array}{l}-0.157^{*} \\
(0.078)\end{array}$ \\
\hline Second wealth quartile & $\begin{array}{l}0.753 * * * \\
(0.249)\end{array}$ & $\begin{array}{l}0.731 * * * \\
(0.255)\end{array}$ & $\begin{array}{l}0.706 * * \\
(0.258)\end{array}$ & $\begin{array}{l}0.688 * * \\
(0.259)\end{array}$ & $\begin{array}{c}0.784 * * * \\
(0.225)\end{array}$ & $\begin{array}{c}0.751 * * * \\
(0.227)\end{array}$ & $\begin{array}{c}0.710 * * * \\
(0.232)\end{array}$ & $\begin{array}{c}0.690 * * * \\
(0.229)\end{array}$ \\
\hline Third wealth quartile & $\begin{array}{c}1.305 * * * \\
(0.257)\end{array}$ & $\begin{array}{c}1.271 * * * \\
(0.269)\end{array}$ & $\begin{array}{c}1.280 * * * \\
(0.271)\end{array}$ & $\begin{array}{c}1.241 * * * \\
(0.280)\end{array}$ & $\begin{array}{c}1.345^{* * *} \\
(0.178)\end{array}$ & $\begin{array}{c}1.289 * * * \\
(0.186)\end{array}$ & $\begin{array}{c}1.267 * * * \\
(0.190)\end{array}$ & $\begin{array}{c}1.222 * * * \\
(0.195)\end{array}$ \\
\hline Fourth wealth quartile & $\begin{array}{c}1.853 * * * \\
(0.301)\end{array}$ & $\begin{array}{c}1.809 * * * \\
(0.308)\end{array}$ & $\begin{array}{c}1.861 * * * \\
(0.331)\end{array}$ & $\begin{array}{c}1.802 * * * \\
(0.330)\end{array}$ & $\begin{array}{c}1.994 * * * \\
(0.266)\end{array}$ & $\begin{array}{c}1.916 * * * \\
(0.285)\end{array}$ & $\begin{array}{c}1.955 * * * \\
(0.302)\end{array}$ & $\begin{array}{c}1.881 * * * \\
(0.311)\end{array}$ \\
\hline Household hire servant & $\begin{array}{c}0.847 * * \\
(0.410)\end{array}$ & $\begin{array}{l}0.846^{* * *} \\
(0.399)\end{array}$ & $\begin{array}{l}0.891 * * \\
(0.394)\end{array}$ & $\begin{array}{l}0.879 * * \\
(0.384)\end{array}$ & $\begin{array}{l}0.777 * \\
(0.404)\end{array}$ & $\begin{array}{l}0.793^{*} \\
(0.389)\end{array}$ & $\begin{array}{l}0.828 * * \\
(0.389)\end{array}$ & $\begin{array}{l}0.832 * * \\
(0.377)\end{array}$ \\
\hline \multirow{2}{*}{$\begin{array}{l}\text { Household possessing } \\
\text { car or bike }\end{array}$} & 0.044 & 0.041 & 0.068 & 0.059 & 0.209 & 0.216 & 0.230 & 0.232 \\
\hline & $(0.252)$ & $(0.242)$ & $(0.247)$ & $(0.236)$ & $(0.202)$ & $(0.198)$ & $(0.202)$ & $(0.198)$ \\
\hline Muslim household & $\begin{array}{c}0.673 \\
(0.427)\end{array}$ & $\begin{array}{c}0.666 \\
(0.430)\end{array}$ & $\begin{array}{c}0.626 \\
(0.420)\end{array}$ & $\begin{array}{c}0.623 \\
(0.420)\end{array}$ & $\begin{array}{c}0.851 * * \\
(0.311)\end{array}$ & $\begin{array}{c}0.850^{* *} \\
(0.316)\end{array}$ & $\begin{array}{c}0.796 * * \\
(0.306)\end{array}$ & $\begin{array}{l}0.804 * * \\
(0.309)\end{array}$ \\
\hline \multirow[t]{2}{*}{$\begin{array}{l}\text { Other religion } \\
\text { household }\end{array}$} & 0.255 & 0.276 & 0.252 & 0.289 & 0.166 & 0.160 & 0.162 & 0.167 \\
\hline & $(0.338)$ & $(0.336)$ & $(0.353)$ & $(0.351)$ & $(0.385)$ & $(0.384)$ & $(0.394)$ & $(0.393)$ \\
\hline \multirow[t]{2}{*}{$\begin{array}{l}\text { Share of expenditure } \\
\text { on eating out }\end{array}$} & $-0.035 * * *$ & $-0.035 * * *$ & $-0.036 * * *$ & $-0.035 * * *$ & $-0.025 * * *$ & $-0.026 * * *$ & $-0.026 * * *$ & $-0.026 * * *$ \\
\hline & $(0.012)$ & $(0.011)$ & $(0.012)$ & $(0.012)$ & $(0.009)$ & $(0.009)$ & $(0.009)$ & $(0.009)$ \\
\hline Year (2011-12) & $\begin{array}{l}0.863 * * * \\
(0.234)\end{array}$ & $\begin{array}{c}0.878 * * * \\
(0.223)\end{array}$ & $\begin{array}{c}0.824 * * * \\
(0.235)\end{array}$ & $\begin{array}{c}0.851 * * * \\
(0.222)\end{array}$ & $\begin{array}{c}0.895 * * * \\
(0.178)\end{array}$ & $\begin{array}{c}0.905 * * * \\
(0.169)\end{array}$ & $\begin{array}{c}0.858 * * * \\
(0.186)\end{array}$ & $\begin{array}{c}0.877 * * * \\
(0.174)\end{array}$ \\
\hline Constant & $\begin{array}{c}13.917 * * * \\
(1.530)\end{array}$ & $\begin{array}{c}14.034 * * * \\
(1.539)\end{array}$ & $\begin{array}{c}14.047 * * * \\
(1.509)\end{array}$ & $\begin{array}{c}14.175 * * * \\
(1.505) \\
\end{array}$ & $\begin{array}{c}13.781 * * * \\
(1.600) \\
\end{array}$ & $\begin{array}{c}13.959 * * * \\
(1.614) \\
\end{array}$ & $\begin{array}{c}14.144 * * * \\
(1.685) \\
\end{array}$ & $\begin{array}{c}14.257 * * * \\
(1.674) \\
\end{array}$ \\
\hline Sample size & 2,353 & 2,353 & 2,353 & 2,353 & 3,076 & 3,076 & 3,076 & 3,076 \\
\hline
\end{tabular}

Notes: Dependent variable is BMI. OLS results are presented. Sample restricted to 18-60-year-old working urban married women at the time of survey in IHDS1 and IHDS2.The regressions also include a set of state dummies not reported here. English speaking ability and activity status of spouse are used as instruments. Standard errors clustered at the state level are in parenthesis. $p$-values are reported in square brackets. Significance: ${ }^{*} p<0.10,{ }^{* *} p<0.05,{ }^{* * *} p<0.01$. 
Table A5: Regression of BMI on labour market sector of work and intensity. Married sample with working and non-working spouses.

\begin{tabular}{|c|c|c|c|c|}
\hline & \multicolumn{2}{|c|}{ Definition 1} & \multicolumn{2}{|c|}{ Definition 2} \\
\hline & OLS & IV & OLS & IV \\
\hline & (1) & $(2)$ & (3) & (4) \\
\hline \multicolumn{5}{|l|}{ Panel A: Urban Working Men } \\
\hline Blue collar & $\begin{array}{c}-0.309 * * * \\
(0.091)\end{array}$ & $\begin{array}{l}-2.145 * * * \\
(0.661)\end{array}$ & $\begin{array}{c}-0.332 * * * \\
(0.073)\end{array}$ & $\begin{array}{l}-2.330 * * * \\
(0.770)\end{array}$ \\
\hline Constant & $\begin{array}{c}17.253^{* * *} \\
(0.961)\end{array}$ & & $\begin{array}{c}17.158 * * * \\
(0.909)\end{array}$ & \\
\hline First Stage F-statistic & & $\begin{array}{c}58.18 \\
{[0.000]}\end{array}$ & & $\begin{array}{c}77.38 \\
{[0.000]}\end{array}$ \\
\hline Hansen's $J$ Chi-squared statistic & & $\begin{array}{c}7.776 \\
{[0.051]}\end{array}$ & & $\begin{array}{c}7.013 \\
{[0.071]}\end{array}$ \\
\hline Sample size & 4,264 & 4,264 & 4,463 & 4,463 \\
\hline \multicolumn{5}{|l|}{$\begin{array}{l}\text { Panel B: Urban Working Men } \\
\text { Aged 18-60 }\end{array}$} \\
\hline MET & $\begin{array}{c}-0.103 \\
(0.067)\end{array}$ & $\begin{array}{c}-0.900 * * * \\
(0.303)\end{array}$ & $\begin{array}{c}-0.096 \\
(0.060)\end{array}$ & $\begin{array}{c}-0.943 * * * \\
(0.314)\end{array}$ \\
\hline Constant & $\begin{array}{c}17.323 * * * \\
(1.026)\end{array}$ & & $\begin{array}{c}17.188 * * * \\
(0.982)\end{array}$ & \\
\hline First Stage F-statistic & & $\begin{array}{c}28.75 \\
{[0.000]}\end{array}$ & & $\begin{array}{c}55.16 \\
{[0.000]}\end{array}$ \\
\hline Hansen's $J$ Chi-squared statistic & & $\begin{array}{c}8.068 \\
{[0.044]} \\
\end{array}$ & & $\begin{array}{c}7.161 \\
{[0.067]} \\
\end{array}$ \\
\hline Sample size & 4,264 & 4,264 & 4,463 & 4,463 \\
\hline
\end{tabular}

Notes: Dependent variable is BMI. OLS and IV regression results presented. In Panel A and Panel B, sample restricted to 18-60-year-old working urban married men in IHDS2. The regressions include individual (age, age square, years of education, marital status, whether or not the individual consumes tobacco, number of children, the average number of hours spent watching television) and household level (dummies for wealth quartiles, whether or not the household has domestic help, whether the household owns a car or a motor cycle, household religions, the share of total expenditure on eating outside) controls, and a set of state dummies. English speaking ability and activity status of spouse (including non-working spouses as well) are used as instruments. Standard errors clustered at the state level are in parenthesis. $p$-values are reported in square brackets. Significance: ${ }^{*} p<0.10,{ }^{* * *} p<0.05,{ }^{* * *} p<0.01$. 
APPENDIX B. FULL SET OF RESULTS

Table B1: Regression of BMI on labour market sector of work and intensity. Urban Working Women aged $18-60$.

\begin{tabular}{|c|c|c|c|c|c|c|c|c|}
\hline & \multicolumn{4}{|c|}{ Definition 1} & \multicolumn{4}{|c|}{ Definition 2} \\
\hline & (1) & (2) & (3) & (4) & (5) & (6) & (7) & $(8)$ \\
\hline \multirow[t]{2}{*}{ Blue Collar } & $-0.439 * *$ & & & & $-0.413^{*}$ & & & \\
\hline & $(0.193)$ & & & & $(0.202)$ & & & \\
\hline \multirow[t]{2}{*}{ Medium Activity } & & -0.287 & & & & -0.133 & & \\
\hline & & $(0.291)$ & & & & $(0.271)$ & & \\
\hline \multirow[t]{2}{*}{ High Activity } & & $-0.537 * * *$ & & & & $-0.553 * * *$ & & \\
\hline & & $(0.160)$ & & & & $(0.190)$ & & \\
\hline \multirow{2}{*}{$\begin{array}{l}\text { Physical intensity } \\
\text { (in MET) }\end{array}$} & & & $-0.261 * * *$ & & & & $-0.250 * * *$ & \\
\hline & & & $(0.060)$ & & & & $(0.061)$ & \\
\hline \multirow[t]{2}{*}{ Moderate Intensity } & & & & -0.373 & & & & $-0.439 *$ \\
\hline & & & & $(0.225)$ & & & & $(0.243)$ \\
\hline \multirow[t]{2}{*}{ Vigorous Intensity } & & & & $-0.796 * * *$ & & & & $-0.762 * * *$ \\
\hline & & & & $(0.161)$ & & & & $(0.120)$ \\
\hline \multirow[t]{2}{*}{ Age } & $0.338 * * *$ & $0.337 * * *$ & $0.346 * * *$ & $0.344 * * *$ & $0.367 * * *$ & $0.362 * * *$ & $0.368 * * *$ & $0.368 * * *$ \\
\hline & $(0.052)$ & $(0.053)$ & $(0.053)$ & $(0.052)$ & $(0.056)$ & $(0.057)$ & $(0.056)$ & $(0.056)$ \\
\hline \multirow[t]{2}{*}{ Age square } & $-0.003 * * *$ & $-0.003 * * *$ & $-0.003 * * *$ & $-0.003 * * *$ & $-0.003 * * *$ & $-0.003 * * *$ & $-0.003 * * *$ & $-0.003 * * *$ \\
\hline & $(0.001)$ & $(0.001)$ & $(0.001)$ & $(0.001)$ & $(0.001)$ & $(0.001)$ & $(0.001)$ & $(0.001)$ \\
\hline \multirow[t]{2}{*}{ Years of education } & 0.023 & 0.024 & 0.022 & $0.026^{*}$ & $0.025^{*}$ & $0.026^{*}$ & 0.021 & 0.024 \\
\hline & $(0.016)$ & $(0.016)$ & $(0.014)$ & $(0.015)$ & $(0.015)$ & $(0.015)$ & $(0.013)$ & $(0.014)$ \\
\hline \multirow[t]{2}{*}{ Married } & 0.115 & 0.136 & 0.091 & 0.093 & 0.048 & 0.094 & 0.060 & 0.047 \\
\hline & $(0.161)$ & $(0.153)$ & $(0.158)$ & $(0.157)$ & $(0.172)$ & $(0.163)$ & $(0.172)$ & $(0.172)$ \\
\hline \multirow[t]{2}{*}{ Smoke tobacco } & 0.101 & 0.108 & 0.074 & 0.086 & -0.198 & -0.182 & -0.203 & -0.193 \\
\hline & $(0.401)$ & $(0.406)$ & $(0.407)$ & $(0.404)$ & $(0.267)$ & $(0.272)$ & $(0.275)$ & $(0.271)$ \\
\hline \multirow[t]{2}{*}{ Hours watching Television } & $0.060 *$ & $0.064 *$ & 0.054 & 0.053 & $0.073 * * *$ & $0.079 * * *$ & $0.069 * *$ & $0.067 * *$ \\
\hline & $(0.034)$ & $(0.034)$ & $(0.035)$ & $(0.035)$ & $(0.023)$ & $(0.024)$ & $(0.025)$ & $(0.025)$ \\
\hline \multirow[t]{2}{*}{ Number of children } & -0.110 & -0.111 & -0.105 & -0.104 & $-0.129 *$ & $-0.130^{*}$ & $-0.125^{*}$ & $-0.124 *$ \\
\hline & $(0.073)$ & $(0.073)$ & $(0.074)$ & $(0.073)$ & $(0.069)$ & $(0.069)$ & $(0.070)$ & $(0.069)$ \\
\hline \multirow[t]{2}{*}{ Second wealth quartile } & $0.630 * * *$ & $0.617 * * *$ & $0.546 * * *$ & $0.594 * * *$ & $0.694 * * *$ & $0.675^{* * *}$ & $0.600 * * *$ & $0.645 * * *$ \\
\hline & $(0.161)$ & $(0.169)$ & $(0.165)$ & $(0.172)$ & $(0.166)$ & $(0.172)$ & $(0.173)$ & $(0.178)$ \\
\hline \multirow[t]{2}{*}{ Third wealth quartile } & $1.091 * * *$ & $1.077 * * *$ & $0.993 * * *$ & $1.081 * * *$ & $1.180 * * *$ & $1.155^{* * *}$ & $1.062 * * *$ & $1.136 * * *$ \\
\hline & $(0.222)$ & $(0.223)$ & $(0.220)$ & $(0.216)$ & $(0.199)$ & $(0.195)$ & $(0.192)$ & $(0.198)$ \\
\hline \multirow[t]{2}{*}{ Fourth wealth quartile } & $1.810 * * *$ & $1.799 * * *$ & $1.748 * * *$ & $1.839 * * *$ & $1.978 * * *$ & $1.955^{* * *}$ & $1.890 * * *$ & $1.974 * * *$ \\
\hline & $(0.314)$ & $(0.317)$ & $(0.331)$ & $(0.328)$ & $(0.262)$ & $(0.262)$ & $(0.278)$ & $(0.280)$ \\
\hline \multirow[t]{2}{*}{ Household hire servant } & $0.914 * *$ & $0.914 * *$ & $0.964 * *$ & $0.954 * *$ & $0.900 * *$ & $0.901 * *$ & $0.953 * *$ & $0.943 * *$ \\
\hline & $(0.422)$ & $(0.421)$ & $(0.409)$ & $(0.412)$ & $(0.390)$ & $(0.389)$ & $(0.384)$ & $(0.382)$ \\
\hline \multirow{2}{*}{$\begin{array}{l}\text { Household possessing car } \\
\text { or bike }\end{array}$} & 0.261 & 0.267 & 0.273 & $0.282 *$ & $0.299 *$ & $0.311 * *$ & $0.313 * *$ & $0.314 * *$ \\
\hline & $(0.165)$ & $(0.165)$ & $(0.165)$ & $(0.161)$ & $(0.147)$ & $(0.146)$ & $(0.146)$ & $(0.144)$ \\
\hline Muslim household & 0.319 & 0.338 & 0.250 & 0.262 & $0.455 * *$ & $0.484 * *$ & $0.380^{*}$ & $0.383 * *$ \\
\hline & $(0.250)$ & $(0.243)$ & $(0.232)$ & $(0.231)$ & $(0.202)$ & $(0.200)$ & $(0.186)$ & $(0.183)$ \\
\hline Other religion household & -0.060 & -0.061 & -0.036 & -0.046 & -0.105 & -0.102 & -0.083 & -0.093 \\
\hline & $(0.248)$ & $(0.247)$ & $(0.239)$ & $(0.245)$ & $(0.245)$ & $(0.243)$ & $(0.244)$ & $(0.246)$ \\
\hline Share of expenditure on & $-0.041 * * *$ & $-0.041 * * *$ & $-0.041 * * *$ & $-0.042 * * *$ & $-0.035 * * *$ & $-0.036 * * *$ & $-0.036^{* * *}$ & $-0.037 * * *$ \\
\hline & $(0.013)$ & $(0.013)$ & $(0.013)$ & $(0.013)$ & $(0.012)$ & $(0.012)$ & $(0.012)$ & $(0.012)$ \\
\hline Year (2011-12) & $0.697 * * *$ & $0.693 * * *$ & $0.678 * * *$ & $0.672 * * *$ & $0.730 * * *$ & $0.718 * * *$ & $0.706^{* * * *}$ & $0.705 * * *$ \\
\hline & $(0.229)$ & $(0.230)$ & $(0.223)$ & $(0.220)$ & $(0.199)$ & $(0.201)$ & $(0.200)$ & $(0.198)$ \\
\hline Constant & $13.926 * * *$ & $13.935 * * *$ & $14.357 * * *$ & $13.679 * * *$ & $13.265 * * *$ & $13.321 * * *$ & $13.841 * * *$ & $13.193 * * *$ \\
\hline & $(0.982)$ & $(0.998)$ & $(1.018)$ & $(0.904)$ & $(1.104)$ & $(1.115)$ & $(1.102)$ & $(1.022)$ \\
\hline Sample size & 3,743 & 3,743 & 3,743 & 3,743 & 4,574 & 4,574 & 4,574 & 4,574 \\
\hline
\end{tabular}

Notes: Dependent variable is BMI. OLS regression results presented. Sample restricted to 18-60-year-old working urban women at the time of survey in IHDS1 and IHDS2. The regressions also control for a set of state dummies. Standard errors clustered at the state level are in parenthesis. Significance: ${ }^{*} p<0.10$, ${ }^{* *} p<0.05,{ }^{* * *} p<0.01$. 
Table B2: Regression of BMI on labour market sector of work and intensity. Married Urban Working Women aged 18-60.

\begin{tabular}{|c|c|c|c|c|c|c|c|c|}
\hline & \multicolumn{4}{|c|}{ Definition 1} & \multicolumn{4}{|c|}{ Definition 2} \\
\hline & OLS & IV & OLS & IV & OLS & IV & OLS & IV \\
\hline & (1) & (2) & (3) & (4) & (5) & (6) & (7) & (8) \\
\hline Blue collar & $\begin{array}{r}-0.553 * * \\
(0.212)\end{array}$ & $\begin{array}{c}-1.008 * * \\
(0.429)\end{array}$ & & & $\begin{array}{c}-0.499 * * \\
(0.206)\end{array}$ & $\begin{array}{l}-0.825^{*} \\
(0.443)\end{array}$ & & \\
\hline MET & & & $\begin{array}{c}-0.174 * * * \\
(0.059)\end{array}$ & $\begin{array}{c}-0.514 * * \\
(0.223)\end{array}$ & & & $\begin{array}{c}-0.192 * * * \\
(0.064)\end{array}$ & $\begin{array}{c}-0.636 * * * \\
(0.185)\end{array}$ \\
\hline Age & $\begin{array}{c}0.383 * * * \\
(0.065)\end{array}$ & $\begin{array}{c}0.386 * * * \\
(0.063)\end{array}$ & $\begin{array}{c}0.385 * * * \\
(0.066)\end{array}$ & $\begin{array}{c}0.395 * * * \\
(0.062)\end{array}$ & $\begin{array}{c}0.371 * * * \\
(0.071)\end{array}$ & $\begin{array}{c}0.373 * * * \\
(0.070)\end{array}$ & $\begin{array}{c}0.371 * * * \\
(0.071)\end{array}$ & $\begin{array}{c}0.377 * * * \\
(0.069)\end{array}$ \\
\hline Age square & $\begin{array}{c}-0.004 * * * \\
(0.001)\end{array}$ & $\begin{array}{c}-0.004 * * * \\
(0.001)\end{array}$ & $\begin{array}{c}-0.004 * * * \\
(0.001)\end{array}$ & $\begin{array}{c}-0.004 * * * \\
(0.001)\end{array}$ & $\begin{array}{c}-0.004 * * * \\
(0.001)\end{array}$ & $\begin{array}{c}-0.004 * * * \\
(0.001)\end{array}$ & $\begin{array}{c}-0.004 * * * \\
(0.001)\end{array}$ & $\begin{array}{c}-0.004 * * * \\
(0.001)\end{array}$ \\
\hline Years of education & $\begin{array}{c}0.034 * * \\
(0.015)\end{array}$ & $\begin{array}{c}0.017 \\
(0.019)\end{array}$ & $\begin{array}{c}0.043 * * * \\
(0.014)\end{array}$ & $\begin{array}{c}0.022 \\
(0.019)\end{array}$ & $\begin{array}{c}0.035 * * * \\
(0.012)\end{array}$ & $\begin{array}{c}0.023 \\
(0.018)\end{array}$ & $\begin{array}{c}0.038 * * * \\
(0.011)\end{array}$ & $\begin{array}{c}0.003 \\
(0.018)\end{array}$ \\
\hline Married & $\begin{array}{l}-0.210 \\
(0.640)\end{array}$ & $\begin{array}{l}-0.202 \\
(0.630)\end{array}$ & $\begin{array}{l}-0.249 \\
(0.632)\end{array}$ & $\begin{array}{l}-0.307 \\
(0.607)\end{array}$ & $\begin{array}{l}-0.515 \\
(0.403)\end{array}$ & $\begin{array}{l}-0.516 \\
(0.393)\end{array}$ & $\begin{array}{l}-0.526 \\
(0.405)\end{array}$ & $\begin{array}{l}-0.556 \\
(0.399)\end{array}$ \\
\hline Smokes tobacco & $\begin{array}{c}0.099 \\
(0.064)\end{array}$ & $\begin{array}{c}0.104 \\
(0.064)\end{array}$ & $\begin{array}{c}0.090 \\
(0.065)\end{array}$ & $\begin{array}{c}0.083 \\
(0.068)\end{array}$ & $\begin{array}{c}0.086 * * \\
(0.038)\end{array}$ & $\begin{array}{c}0.087 * * \\
(0.039)\end{array}$ & $\begin{array}{l}0.081 * \\
(0.040)\end{array}$ & $\begin{array}{c}0.074 \\
(0.046)\end{array}$ \\
\hline $\begin{array}{l}\text { Hours watching } \\
\text { Television }\end{array}$ & $(0.084)$ & $(0.084)$ & $(0.084)$ & $(0.085)$ & $\begin{array}{l}-0.155^{*} \\
(0.079)\end{array}$ & $\begin{array}{c}-0.154 * * \\
(0.078)\end{array}$ & $\begin{array}{l}-0.154 * \\
(0.078)\end{array}$ & $\begin{array}{l}-0.148 * \\
(0.078)\end{array}$ \\
\hline Number of children & $\begin{array}{l}0.751 * * * \\
(0.248)\end{array}$ & $\begin{array}{c}0.715 * * * \\
(0.264)\end{array}$ & $\begin{array}{c}0.702 * * \\
(0.258)\end{array}$ & $\begin{array}{c}0.519 \\
(0.319)\end{array}$ & $\begin{array}{c}0.788 * * * \\
(0.222)\end{array}$ & $\begin{array}{c}0.766 * * * \\
(0.232)\end{array}$ & $\begin{array}{c}0.711 * * * \\
(0.230)\end{array}$ & $\begin{array}{c}0.457 \\
(0.295)\end{array}$ \\
\hline Second wealth quartile & $\begin{array}{c}1.302 * * * \\
(0.258)\end{array}$ & $\begin{array}{c}1.211 * * * \\
(0.313)\end{array}$ & $\begin{array}{c}1.275 * * * \\
(0.272)\end{array}$ & $\begin{array}{c}1.008 * * * \\
(0.370)\end{array}$ & $\begin{array}{c}1.352 * * * \\
(0.175)\end{array}$ & $\begin{array}{c}1.295 * * * \\
(0.214)\end{array}$ & $\begin{array}{c}1.268 * * * \\
(0.189)\end{array}$ & $\begin{array}{c}0.872 * * * \\
(0.283)\end{array}$ \\
\hline Third wealth quartile & $\begin{array}{c}1.857 * * * \\
(0.295)\end{array}$ & $\begin{array}{c}1.726 * * * \\
(0.360)\end{array}$ & $\begin{array}{c}1.875 * * * \\
(0.323)\end{array}$ & $\begin{array}{c}1.596 * * * \\
(0.403)\end{array}$ & $\begin{array}{c}1.988 * * * \\
(0.262)\end{array}$ & $\begin{array}{c}1.890 * * * \\
(0.331)\end{array}$ & $\begin{array}{c}1.952 * * * \\
(0.297)\end{array}$ & $\begin{array}{c}1.524 * * * \\
(0.388)\end{array}$ \\
\hline Fourth wealth quartile & $\begin{array}{c}0.850 * * \\
(0.409)\end{array}$ & $\begin{array}{c}0.838 * * \\
(0.400)\end{array}$ & $\begin{array}{c}0.899 * * \\
(0.392)\end{array}$ & $\begin{array}{c}0.968 * * * \\
(0.350)\end{array}$ & $\begin{array}{l}0.768^{*} \\
(0.399)\end{array}$ & $\begin{array}{l}0.758^{*} \\
(0.393)\end{array}$ & $\begin{array}{c}0.826 * * \\
(0.383)\end{array}$ & $\begin{array}{c}0.922 * * * \\
(0.344)\end{array}$ \\
\hline $\begin{array}{l}\text { Household has } \\
\text { domestic help }\end{array}$ & 0.047 & 0.013 & 0.078 & 0.055 & 0.204 & 0.186 & 0.228 & 0.221 \\
\hline & $(0.248)$ & $(0.236)$ & $(0.242)$ & $(0.240)$ & $(0.200)$ & $(0.195)$ & $(0.200)$ & $(0.199)$ \\
\hline $\begin{array}{l}\text { Household possessing } \\
\text { car or bike }\end{array}$ & 0.671 & 0.648 & 0.624 & 0.474 & $0.851 * *$ & $0.836^{* * *}$ & $0.796 * *$ & $0.617 * *$ \\
\hline & $(0.430)$ & $(0.427)$ & $(0.421)$ & $(0.418)$ & $(0.311)$ & $(0.312)$ & $(0.305)$ & $(0.309)$ \\
\hline Muslim household & $\begin{array}{c}0.260 \\
(0.337)\end{array}$ & $\begin{array}{c}0.257 \\
(0.317)\end{array}$ & $\begin{array}{c}0.266 \\
(0.353)\end{array}$ & $\begin{array}{c}0.268 \\
(0.349)\end{array}$ & $\begin{array}{c}0.156 \\
(0.385)\end{array}$ & $\begin{array}{c}0.161 \\
(0.369)\end{array}$ & $\begin{array}{c}0.159 \\
(0.395)\end{array}$ & $\begin{array}{c}0.187 \\
(0.393)\end{array}$ \\
\hline $\begin{array}{l}\text { Other religion } \\
\text { household }\end{array}$ & $-0.035^{* * *}$ & $-0.035^{* * *}$ & $-0.036 * * *$ & $-0.035 * * *$ & $-0.025^{* * *}$ & $-0.025 * * *$ & $-0.026 * * *$ & $-0.025 * * *$ \\
\hline & $(0.012)$ & $(0.011)$ & $(0.012)$ & $(0.013)$ & $(0.009)$ & $(0.009)$ & $(0.009)$ & $(0.009)$ \\
\hline $\begin{array}{l}\text { Share of expenditure } \\
\text { on eating out }\end{array}$ & $0.865^{* * *}$ & $0.904 * * *$ & $0.826^{* * *}$ & $0.844 * * *$ & $0.892 * * *$ & $0.921 * * *$ & $0.857 * * *$ & $0.877 * * *$ \\
\hline Constant & $(0.232)$ & $(0.212)$ & $\begin{array}{c}(0.234) \\
14.038 * * * \\
(1.504)\end{array}$ & $(0.228)$ & $(0.176)$ & $\begin{array}{c}(0.152) \\
14.147 * * * \\
(1.678)\end{array}$ & $(0.185)$ & $(0.186)$ \\
\hline Sample size & 2,353 & 2,353 & 2,353 & 2,353 & 3,076 & 3,076 & 3,076 & 3,076 \\
\hline
\end{tabular}

Notes: Dependent variable is BMI. OLS and IV regression results presented. Sample restricted to 18-60-year-old working urban married women at the time of survey in IHDS1 and IHDS2. The regressions also include a set of state dummies not reported here. English speaking ability and activity status of spouse are used as instruments. Standard errors clustered at the state level are in parenthesis. $p$-values are reported in square brackets. Significance: ${ }^{*} p<0.10,{ }^{* *} p<0.05,{ }^{* * *} p<0.01$. 
Table B3: Regression of BMI on labour market sector of work and intensity. Urban Men aged 18-60.

\begin{tabular}{|c|c|c|c|c|c|c|c|c|}
\hline & \multicolumn{4}{|c|}{ Definition 1} & \multicolumn{4}{|c|}{ Definition 2} \\
\hline & (1) & (2) & (3) & (4) & (5) & (6) & (7) & (8) \\
\hline \multicolumn{9}{|l|}{ Urban Working Men } \\
\hline Blue Collar & $\begin{array}{c}-0.334 * * * \\
(0.117)\end{array}$ & & & & $\begin{array}{c}-0.335 * * * \\
(0.111)\end{array}$ & & & \\
\hline Medium Activity & & -0.066 & & & & -0.077 & & \\
\hline & & $(0.122)$ & & & & $(0.128)$ & & \\
\hline $\begin{array}{l}\text { Physical intensity } \\
\text { (in MET) }\end{array}$ & & & $\begin{array}{l}-0.116 \\
(0.072)\end{array}$ & & & & $\begin{array}{l}-0.119 * \\
(0.066)\end{array}$ & \\
\hline Moderate Intensity & & & & $\begin{array}{l}-0.279 * \\
(0.144)\end{array}$ & & & & $\begin{array}{c}-0.275^{* *} \\
(0.122)\end{array}$ \\
\hline Age square & $\begin{array}{c}-0.003 * * * \\
(0.000)\end{array}$ & $\begin{array}{c}-0.003 * * * \\
(0.000)\end{array}$ & $\begin{array}{c}-0.003^{* * * *} \\
(0.000)\end{array}$ & $\begin{array}{c}-0.003 * * * \\
(0.000)\end{array}$ & $\begin{array}{c}-0.003 * * * \\
(0.000)\end{array}$ & $\begin{array}{c}-0.003^{* * *} \\
(0.000)\end{array}$ & $\begin{array}{c}-0.003^{* * *} \\
(0.000)\end{array}$ & $\begin{array}{c}-0.003 * * * \\
(0.000)\end{array}$ \\
\hline Years of education & $\begin{array}{c}0.062 * * * \\
(0.016)\end{array}$ & $\begin{array}{l}0.061 * * * \\
(0.016)\end{array}$ & $\begin{array}{c}0.066 * * * \\
(0.015)\end{array}$ & $\begin{array}{c}0.069 * * * \\
(0.014)\end{array}$ & $\begin{array}{c}0.066 * * * \\
(0.015)\end{array}$ & $\begin{array}{c}0.064 * * * \\
(0.016)\end{array}$ & $\begin{array}{c}0.069 * * * \\
(0.015)\end{array}$ & $\begin{array}{l}0.072 * * * \\
(0.013)\end{array}$ \\
\hline Married & $\begin{array}{c}0.680 * * * \\
(0.229)\end{array}$ & $\begin{array}{c}0.670 * * * \\
(0.226)\end{array}$ & $\begin{array}{c}0.675^{* * * *} \\
(0.228)\end{array}$ & $\begin{array}{c}0.671 * * * \\
(0.229)\end{array}$ & $\begin{array}{c}0.736 * * * \\
(0.235)\end{array}$ & $\begin{array}{c}0.727 * * * \\
(0.232)\end{array}$ & $\begin{array}{c}0.730 * * * \\
(0.234)\end{array}$ & $\begin{array}{c}0.727 * * * \\
(0.235)\end{array}$ \\
\hline Smokes tobacco & $\begin{array}{c}-0.486 * * * \\
(0.110)\end{array}$ & $\begin{array}{c}-0.485^{* * *} \\
(0.111)\end{array}$ & $\begin{array}{c}-0.481 * * * \\
(0.111)\end{array}$ & $\begin{array}{c}-0.488 * * * \\
(0.112)\end{array}$ & $\begin{array}{c}-0.484 * * * \\
(0.107)\end{array}$ & $\begin{array}{c}-0.484 * * * \\
(0.108)\end{array}$ & $\begin{array}{c}-0.479 * * * \\
(0.107)\end{array}$ & $\begin{array}{c}-0.486 * * * \\
(0.107)\end{array}$ \\
\hline Hours watching & 0.015 & 0.015 & 0.013 & 0.013 & 0.009 & 0.010 & 0.008 & 0.007 \\
\hline Fourth wealth quartile & $\begin{array}{c}1.135 * * * \\
(0.316)\end{array}$ & $\begin{array}{c}1.091 * * * \\
(0.314)\end{array}$ & $\begin{array}{c}1.135 * * * \\
(0.307)\end{array}$ & $\begin{array}{c}1.176^{* * * *} \\
(0.307)\end{array}$ & $\begin{array}{c}1.060 * * * \\
(0.319)\end{array}$ & $\begin{array}{c}1.020 * * * \\
(0.317)\end{array}$ & $\begin{array}{c}1.058 * * * \\
(0.311)\end{array}$ & $\begin{array}{c}1.095 * * * \\
(0.312)\end{array}$ \\
\hline Household hire servant & $\begin{array}{l}1.094 * * * \\
(0.355)\end{array}$ & $\begin{array}{l}1.102 * * * \\
(0.359)\end{array}$ & $\begin{array}{c}1.100 * * * \\
(0.352)\end{array}$ & $\begin{array}{c}1.092 * * * \\
(0.351)\end{array}$ & $\begin{array}{l}0.992 * * * \\
(0.303)\end{array}$ & $\begin{array}{c}0.998 * * * \\
(0.308)\end{array}$ & $\begin{array}{c}1.000 * * * \\
(0.301)\end{array}$ & $\begin{array}{l}0.996 * * * \\
(0.302)\end{array}$ \\
\hline $\begin{array}{l}\text { Household possessing } \\
\text { car or bike }\end{array}$ & $0.794 * * *$ & $0.796 * * *$ & $0.804 * * *$ & $0.812 * * *$ & $0.842 * * *$ & $0.848 * * *$ & $0.852 * * *$ & $0.858 * * *$ \\
\hline & $(0.209)$ & $(0.207)$ & $(0.209)$ & $(0.212)$ & $(0.191)$ & $(0.190)$ & $(0.194)$ & $(0.195)$ \\
\hline Muslim household & $\begin{array}{c}0.236 \\
(0.288)\end{array}$ & $\begin{array}{c}0.243 \\
(0.284)\end{array}$ & $\begin{array}{c}0.232 \\
(0.289)\end{array}$ & $\begin{array}{c}0.243 \\
(0.287)\end{array}$ & $\begin{array}{c}0.206 \\
(0.284)\end{array}$ & $\begin{array}{c}0.214 \\
(0.280)\end{array}$ & $\begin{array}{c}0.200 \\
(0.283)\end{array}$ & $\begin{array}{c}0.211 \\
(0.280)\end{array}$ \\
\hline Other religion household & $\begin{array}{c}0.147 \\
(0.208)\end{array}$ & $\begin{array}{c}0.162 \\
(0.208)\end{array}$ & $\begin{array}{c}0.166 \\
(0.210)\end{array}$ & $\begin{array}{c}0.170 \\
(0.207)\end{array}$ & $\begin{array}{c}0.183 \\
(0.190)\end{array}$ & $\begin{array}{c}0.192 \\
(0.190)\end{array}$ & $\begin{array}{c}0.200 \\
(0.192)\end{array}$ & $\begin{array}{c}0.204 \\
(0.190)\end{array}$ \\
\hline $\begin{array}{l}\text { Share of expenditure } \\
\text { on eating out }\end{array}$ & -0.002 & -0.003 & -0.002 & -0.002 & -0.004 & -0.005 & -0.004 & -0.003 \\
\hline & $(0.012)$ & $(0.012)$ & $(0.012)$ & $(0.012)$ & $(0.011)$ & $(0.011)$ & $(0.011)$ & $(0.011)$ \\
\hline Constant & $\begin{array}{c}15.647 * * * \\
(0.761)\end{array}$ & $\begin{array}{c}15.641 * * * \\
(0.766)\end{array}$ & $\begin{array}{c}15.706 * * * \\
(0.829)\end{array}$ & $\begin{array}{c}15.431 * * * \\
(0.734)\end{array}$ & $\begin{array}{c}15.322 * * * \\
(0.763)\end{array}$ & $\begin{array}{c}15.321 * * * \\
(0.761)\end{array}$ & $\begin{array}{c}15.392 * * * \\
(0.819)\end{array}$ & $\begin{array}{c}15.097 * * * \\
(0.725)\end{array}$ \\
\hline High - Medium Activity & & $\begin{array}{c}-0.430 * * * \\
(0.136)\end{array}$ & & & & $\begin{array}{c}-0.405^{* * *} \\
(0.140)\end{array}$ & & \\
\hline
\end{tabular}



regressions also control for a set of state dummies. Standard errors clustered at the state level are in parenthesis. Significance: ${ }^{*} p<0.10,{ }^{* *} p<0.05,{ }^{* * *}$ $p<0.01$. 
Table B4: Regression of BMI on labour market sector of work and intensity. Married Urban Working Men $18-60$.

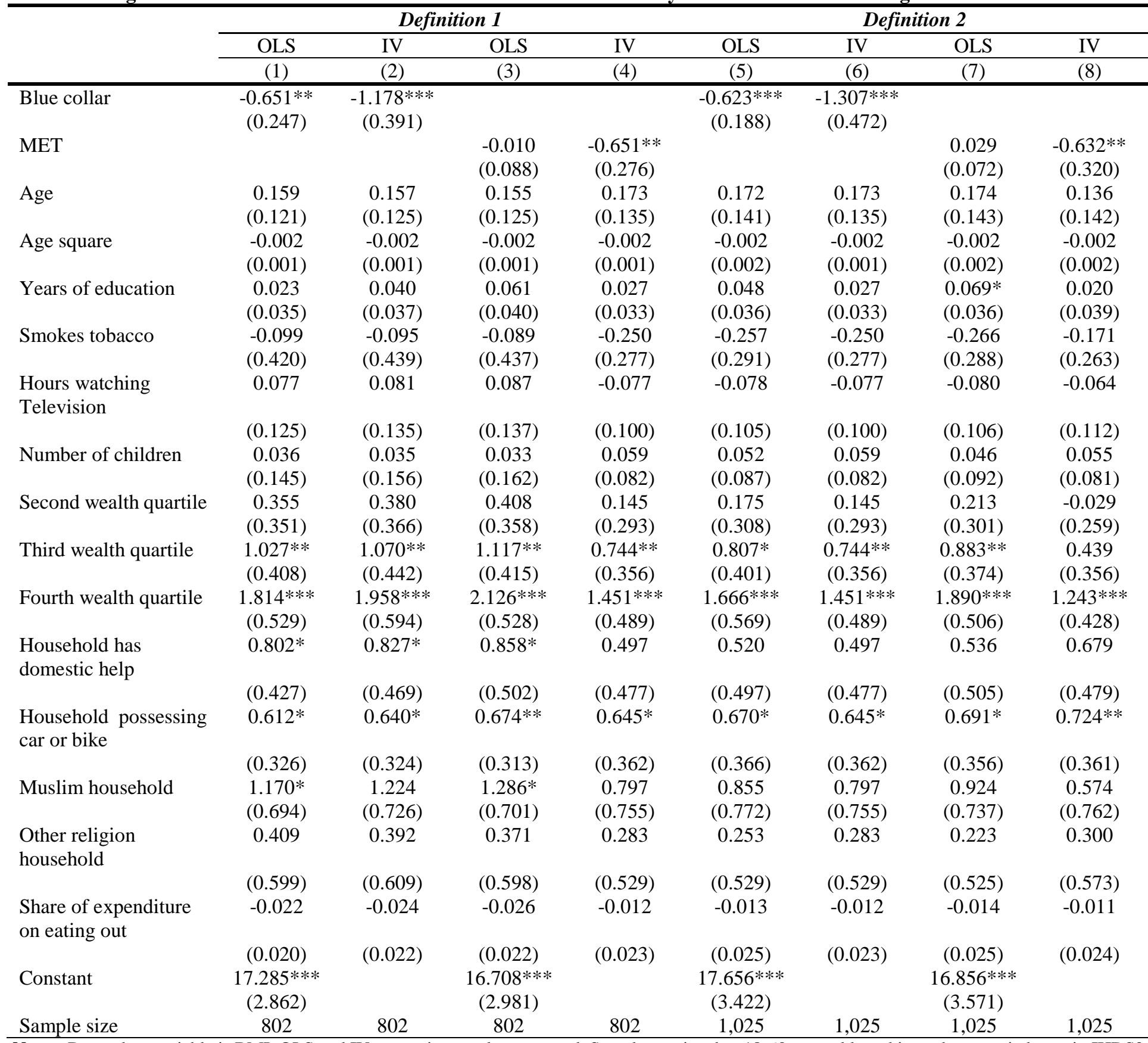

Notes: Dependent variable is BMI. OLS and IV regression results presented. Sample restricted to 18-60-year-old working urban married men in IHDS2. The regressions also include a set of state dummies not reported here. English speaking ability and activity status of spouse are used as instruments. Standard errors clustered at the state level are in parenthesis. $p$-values are reported in square brackets. Significance: ${ }^{*} p<0.10,{ }^{* *} p<0.05,{ }^{* * *} p<0.01$. 